DISEASE, DOWNTURNS, AND WELLBEING:

ECONOMIC HISTORY AND THE LONG-RUN IMPACTS OF COVID-19

\author{
Vellore Arthi \\ John Parman \\ Working Paper 27805 \\ http://www.nber.org/papers/w27805 \\ NATIONAL BUREAU OF ECONOMIC RESEARCH \\ 1050 Massachusetts Avenue \\ Cambridge, MA 02138 \\ September 2020
}

The views expressed herein are those of the authors and do not necessarily reflect the views of the National Bureau of Economic Research.

NBER working papers are circulated for discussion and comment purposes. They have not been peerreviewed or been subject to the review by the NBER Board of Directors that accompanies official NBER publications.

(C) 2020 by Vellore Arthi and John Parman. All rights reserved. Short sections of text, not to exceed two paragraphs, may be quoted without explicit permission provided that full credit, including $\odot$ notice, is given to the source. 
Disease, Downturns, and Wellbeing: Economic History and the Long-Run Impacts of COVID-19 Vellore Arthi and John Parman

NBER Working Paper No. 27805

September 2020

JEL No. I1,I3,J1,J6,N1,N3

\begin{abstract}
$\underline{\text { ABSTRACT }}$
How might COVID-19 affect human capital and wellbeing in the long run? The COVID-19 pandemic has already imposed a heavy human cost — taken together, this public health crisis and its attendant economic downturn appear poised to dwarf the scope, scale, and disruptiveness of most modern pandemics. What evidence we do have about other modern pandemics is largely limited to short-run impacts. Consequently, recent experience can do little to help us anticipate and respond to COVID-19's potential long-run impact on individuals over decades and even generations. History, however, offers a solution. Historical crises offer closer analogues to COVID-19 in each of its key dimensions-as a global pandemic, as a global recession - and offer the runway necessary to study the life-course and intergenerational outcomes. In this paper, we review the evidence on the long-run effects on health, labor, and human capital of both historical pandemics (with a focus on the 1918 Influenza Pandemic) and historical recessions (with a focus on the Great Depression). We conclude by discussing how past crises can inform our approach to COVID-19-helping tell us what to look for, what to prepare for, and what data we ought to collect now.
\end{abstract}

Vellore Arthi

Department of Economics

3151 Social Sciences Plaza

University of California, Irvine

Irvine, CA 92697

varthi@uci.edu

John Parman

Department of Economics

P.O. Box 8795

College of William and Mary

Williamsburg, VA 23187

and NBER

jmparman@wm.edu 


\title{
Disease, Downturns, and Wellbeing: Economic History and the Long-Run Impacts of COVID-19
}

\author{
Vellore Arthi (UC Irvine) \& John Parman (College of William \& Mary, NBER)
}

\section{Introduction}

The health and economic toll of the COVID-19 pandemic continues to expand throughout the globe, impacting countries both rich and poor. As it does so, the virus exposes the strengths and weaknesses of our healthcare systems, political institutions, media, and our economies themselves. Much of the discussion to date has understandably focused on stemming the immediate costs of the COVID-19 crisis: among them, mortality, business failures, job losses, and foreclosures. This pain is salient, and as such, very obviously demands an urgent response. However, there are potential outcomes of the current pandemic which, while perhaps less salient, also merit urgent attention: namely, long-run damage to human capital and wellbeing. It is to these particular long-run effects that we turn our attention in this paper. ${ }^{1}$

The potential for long-run harm to human capital arises from two main facts about the current pandemic. First, key features of COVID-19 - among them its geographic reach, its relatively high ease of transmission, its comparatively low lethality, and its many emerging sequelae - have given rise to widespread and potentially lasting morbidity among its many survivors. Second, the pandemic has sparked an unprecedentedly large downturn, which in its own right has the capacity to permanently scar trajectories of health and income, even for those who do not fall ill themselves. While the costs of these long-run effects may seem far away, they are latent today and could become massive down the line: burdening healthcare systems and government assistance programs, suppressing work capacity and human capital investment, and reducing economic prosperity more generally. Luckily, the returns to avoiding these harms, or to acting swiftly to compensate for them before they have a chance to compound, tend to be much higher the sooner interventions can be made (see, e.g., Heckman, 2007; Almond \& Currie, 2011). Together, the potential for diffuse and latent adverse effects, and the cost-effectiveness of early remediation, suggest that in addition to any efforts to address the immediate pain of the pandemic, our eyes should also be on the future, and actions we can take now to mitigate the long-run pain for affected cohorts, and therefore, the wider economy. But what, exactly, is the long-run human fallout of COVID-19 likely to be-and who will bear the brunt of this crisis? To answer these questions, we need the sort of long-run view that only history can provide.

An obvious starting point is to look to evidence from historical pandemics. Despite potential differences in empirical settings and epidemiological characteristics, the sheer number and diversity of past pandemics means that COVID-19 has many close historical analogues as a health crisis. For instance, while the current pandemic is frequently described as unprecedented, in many ways, its immediate effects on health are not altogether anomalous. With cases first appearing in December 2019, SARS-CoV-2, the pathogen behind COVID-19, spread throughout the world in a matter of weeks, with deadly consequences. By the end of April 2020, with the pandemic still spreading, worldwide cases had topped 3,000,000, and fatalities exceeded 200,000. Cases would exceed 24,000,000 and fatalities would pass 800,00 by late August. ${ }^{2}$ For context, deaths from H1N1 (swine flu) in 2009-10 were similar in magnitude, with estimates of over 200,000 deaths attributable to the virus (Dawood et al., 2012). The Hong Kong Flu of 1968 and the Asian Flu of 1957 were even deadlier, killing 1 million and 2 million people, respectively. Cholera, typhus, smallpox, measles, and tuberculosis all have had high death tolls,

\footnotetext{
${ }^{1}$ For historical insight on COVID-19 in the context of short-run health and economic effects, see, e.g., Beach et al. (2020). For historical insight on COVID-19 as it pertains to potential long-run macroeconomic effects, see, e.g., Barro et al. (2020).

${ }^{2}$ Case and fatality figures come from the Center for Systems Science and Engineering's COVID-19 Dashboard (https://coronavirus.jhu.edu/map.html). It is worth noting that since the COVID-19 pandemic is still unfolding, these statistics underestimate its health toll relative to some "completed" health crises.
} 
including during the 20th century. Reaching even further back, the Black Death left a devasting imprint on the world, killing a third of Europe's population. ${ }^{3}$ Clearly, historical pandemics offer a rich evidence base that can help shed light on the range of possible long-run effects of COVID-19 through morbidity.

However, there is one crucial aspect of the current pandemic that sets it apart from all but the most catastrophic historical disease outbreaks ${ }^{4}$ : the presence of an acute public health crisis alongside massive and widespread economic disruptions. Not just that - it is the fact that this health crisis has precipitated an economic one. To wit, efforts to stop the spread of the virus, alongside failures to contain it, have contributed to a dramatic slowdown of the global economy. Consider, for instance, the economic dislocation experienced in the U.S., a country which quickly came to lead the world in both confirmed COVID-19 cases and deaths. In March and April of 2020, roughly 20 percent of the United States' labor force filed unemployment claims. Double-digit unemployment would continue through the summer. The Dow Jones fell by over 35 percent. For contrast, during 1957 influenza pandemic, responsible for roughly 100,000 deaths in the U.S. (Glezen, 1996; Simonsen et al., 1997), unemployment peaked at 7.4 percent, and the Dow fell 15 percent - certainly a recession, but nothing on the order of what we have already experienced during the COVID-19 outbreak, just a few months in. The unprecedented scale of the COVID-19 economic downturn relative to past pandemics is apparent in Figure 1, which shows the evolution of U.S. GDP over time, with major epidemics highlighted.

\section{Figure 1: U.S. log real GDP per capita with major epidemics highlighted, 1790-2020}

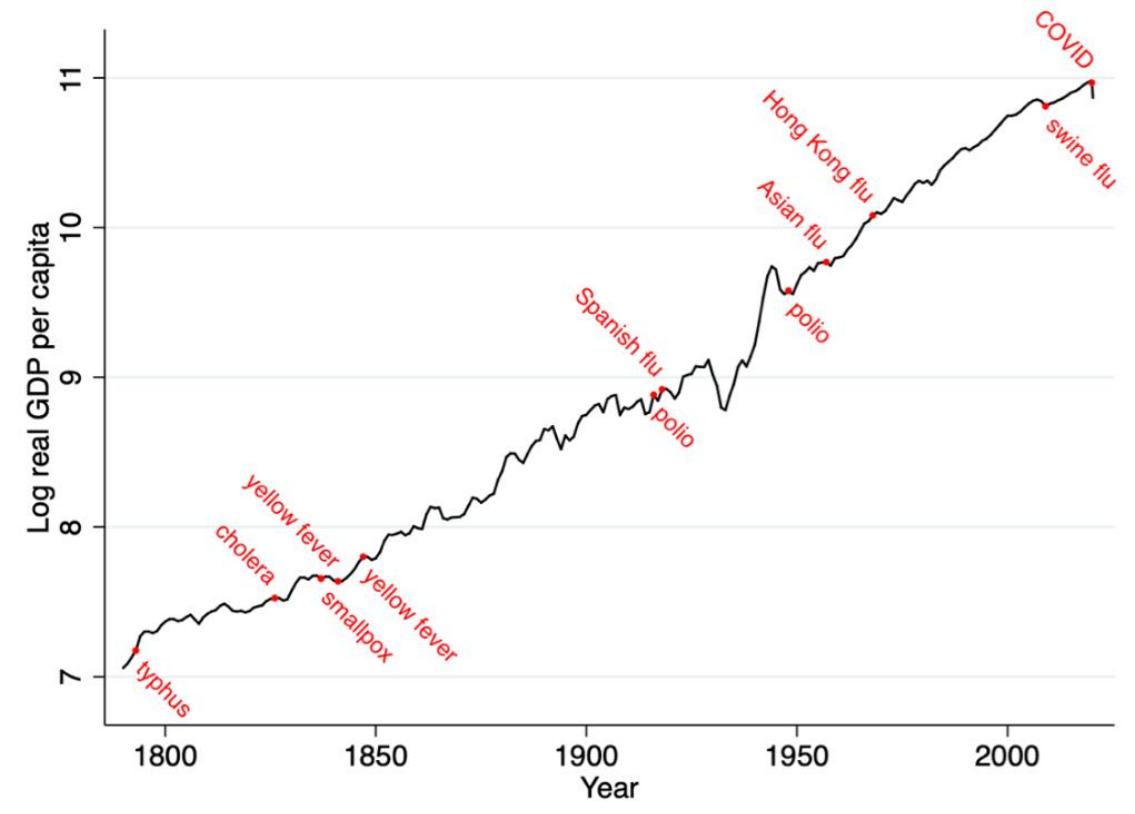

Notes: Annual GDP per capita data for 1790 through 2019 are taken from https://www.measuringworth.com. Quarterly real GDP per capita data for 2019 and 2020 are taken from https://fred.stlouisfed.org/series/A939RX0Q048SBEA and deflated to 2012 dollars to match the historical data.

\footnotetext{
${ }^{3}$ Plague would continue to impact economies into the $20^{\text {th }}$ century, with an outbreak in San Francisco infecting 121 individuals and killing 119 (Echenberg, 2010). The San Francisco outbreak presents interesting parallels to COVID19. Despite health officials identifying the plague and urging action, California's governor, Henry Gage, denied there was an outbreak, partly out of a desire to prevent business losses from a quarantine. It took the intervention of federal authorities and a new governor to implement proper measures to stop the spread of the plague. California officials initially reacted quite differently to COVID-19, swiftly imposing stay-at-home orders. A century later, the calculus of weighing an economic slowdown against the spread of disease has changed. Despite a much larger population, and a much more widespread pandemic, COVID-19 claimed under 100 lives in San Francisco County as of August, 2020.

${ }^{4}$ For instance, the AIDS crisis and the Black Death may be some of the only other major pandemics where mass morbidity and mortality were accompanied by dramatic and widespread economic dislocation.
} 
Clearly, this feature of the current pandemic calls for complementary evidence if we are to understand its potential for long-run harm: there is no suitable all-in-one historical analogue for COVID-19, and evidence from past pandemics alone is likely to understate the potential for damage to (or intervention in) health and welfare through income and labor-market channels. Indeed, to continue with our U.S. example, the twotrillion-dollar Coronavirus Aid, Recovery, and Economic Security Act's closest comparison, is not to be found in past responses to health crises, but rather in the response to past macroeconomic crises-e.g., the American Recovery and Reinvestment Act in the case of the Great Recession, and the New Deal in the case of the Great Depression. Federal outlays as a percentage of GDP rose from 3.3 percent at the start of the Great Depression to 9.8 percent by 1934. The CARES Act alone is equal to roughly 10 percent of 2019 GDP, and this does not account for additional relief likely to be approved. ${ }^{7}$ Asset purchases in response to the Great Recession increased the Federal Reserve's balance sheet from \$0.9 billion in 2007 to $\$ 4.5$ trillion in 2015. That balance sheet has gone from $\$ 4.2$ trillion in February of 2020 to $\$ 7.2$ trillion just four months later. ${ }^{8}$ By nearly any metric, COVID-19 has generated both an economic crisis and a government response of historic scale. Studying how individuals emerged from these primarily economic disasters, and what role government fiscal interventions played in their recovery, may therefore help us flesh out the incomplete perspective we would gain from studying past health shocks alone.

Turning to a combination of historical crises, then-past pandemics and recessions, both-allows us to consider events that in many ways more closely mirror current circumstances, and whose contextual differences can themselves be informative of our current situation First, and most crucially, these events have had time to fully unfold: the short-, medium-, and long-run consequences of these events can be directly observed. Second, the diverse array of historical events, settings, and mechanisms provides a set of reasonable analogues for COVID-19, even as our understanding of COVID-19 evolves. Third, the economic history literature shows how much can be learned with clever analysis of even incomplete or imperfect data. Missing and inaccurate health data is unfortunately directly relevant to assessing the spread of COVID-19, given, for instance, current issues with testing and coordination. Thus, a historical perspective allows us to use rich data to look at not only the short-term effects of crises like COVID-19 on health, labor, and human capital, but also the long-term and intergenerational impacts along these dimensions for both individuals and the wider economy. In so doing, it can offer us insight on the current crisis - telling us what to look for, what to prepare for, and what data we ought to collect now. Put another way, understanding the lingering health and economic impacts of these past crises offers valuable insight for anticipating and responding to the potential long-term impacts of COVID-19.

To examine how history can inform our view of the coronavirus pandemic and associated policy responses as they relate to long-run wellbeing, we begin in Section II by reviewing the features of COVID-19 that will determine its potential health and economic impacts, and placing these features in historical context. Then, in Sections III and IV, respectively, we narrow our focus to two of the closest analogues to the current pandemicone, the 1918 influenza pandemic, which speaks to "direct" health-channel effects; and another, the Great Depression, which speaks to "indirect" effects through the labor market and wider economy. There, we review the economic literature on the short- and long-term effects on individuals and cohorts exposed to these massive shocks, and discuss how these short-run experiences can give rise to lasting, and sometimes hidden, damage. We conclude by discussing what economic historians and researchers of COVID-19 can offer each other.

\footnotetext{
${ }^{7}$ Federal Reserve Bank of St. Louis and U.S. Office of Management and Budget, Federal Net Outlays as Percent of Gross Domestic Product [FYONGDA188S], retrieved from FRED, Federal Reserve Bank of St. Louis; https://fred.stlouisfed.org/series/FYONGDA188S, August 25, 2020.

${ }^{8}$ Retrieved from https://www.federalreserve.gov/monetarypolicy/bst_recenttrends.htm, August 25, 2020.
} 


\section{Features of COVID-19 in Historical Context}

Before we can look to historical evidence on how COVID-19's effects may unfold in the long run, it is useful to fix ideas about key features of the current crisis - its epidemiology, its demographics, and the policy responses to date. Comparing these features to those seen in past pandemics offers a sense of which historical pandemics might serve as the most useful points of reference going forward.

\section{II.a. The Epidemiology of COVID-19}

We draw here on the principles outlined by Morens et al. (2009) to categorize pandemics. They point to eight characteristics common to most accepted definitions of a pandemic: 1) wide geographic extension and 2) disease movement, which speak to the disease's spatial reach; 3) high attack rates and explosiveness, 4) infectiousness, and 5) contagiousness, which speak to how it spreads; 6) severity, which speaks to its potential for population scarring and culling; and 7) minimal population immunity and 8) novelty, which speak to the scope for harm and the speed with which preventive and therapeutic responses can be marshalled. By all measures, COVID-19 presents these hallmark features of a pandemic. Understanding exactly how COVID-19 reflects each dimension is essential for understanding the likely short- and long-run consequences of the pandemic.

\section{II.a.1. Spatial Scope: Geographic Extension and Disease Movement}

The widespread nature of pandemics makes their health and economic impacts particularly devastating: with effects felt everywhere, it becomes increasingly difficult to shift economic activity to, or medical resources from, unaffected areas. While the true extent and timing of COVID-19 cases is yet to be determined, the evidence to date indicates that the global spread of the virus was incredibly rapid. The earliest reported cases appeared in December 2019 in Wuhan, China. That same month, the virus made it to France. By January 2020, there were confirmed cases throughout Asia, Europe, North America, and Africa, and by the end of the month, the number of cases worldwide reached 10,000. In the months that followed, that number rose sharply - first to 85,000 in February, 750,000 in March, and over 3,000,000 by the end of April. As of May 2020, only 12 sovereign states had no confirmed cases, 10 of which are island nations in Oceania. COVID-19 had become a truly global pandemic by the end of spring 2020, and both cases and fatalities would continue to rise across the globe in the months to come.

This feature of COVID-19 surely has much to do with the highly globalized nature of our modern economy. Indeed, we see similar patterns in historical pandemics, reaching as far back as we have had extensive trade routes. ${ }^{10}$ Nearly every country with reliable mortality statistics displayed excess deaths from the 1918 influenza pandemic (Barro et al., 2020). Similarly, the plague pandemic originating in Canton and Hong Kong in 1894 spread to 77 ports across five continents (WHO, 2000), and even the Justinian Plague of 542 reached Asia, Africa, and Europe. Even in a historical era where countries were less tightly integrated than they are today, the only thing that truly spared an area from pandemics was isolation. ${ }^{11}$ With the increase over the last few centuries in both global connectedness and population density, the implications for our current crisis are clear.

\section{II.a.2. Rate of Transmission: Attack Rates, Explosiveness, Infectiousness, and Contagiousness}

The speed with which a disease spreads directly impacts the difficulty of containing it. Indeed, it is these transmissibility-related features that account for many of the public health measures seen in response to the current crisis - some, such as early international travel restrictions, which tried to contain a disease that in

\footnotetext{
${ }^{10}$ Even though world economies are substantially more tightly integrated than in the past, even in the preindustrial era, Alfani \& Murphy (2017) document that it was common for disease to be transmitted along trade routes or through interregional commercial contact. Big trading centers in particular, such as Amsterdam, London, and Venice, frequently faced outbreaks of plague (see Alfani (2013), Biraben (1975), and Curtis (2016) for the underlying studies).

11 The opening up of regions to trade, or conquest, has generated a large literature on the role of disease in shaping economies. See in particular the literature on the Columbian Exchange (Nunn \& Qian, 2010).
} 
many countries was already being spread locally via community transmission; and some, such as stay-athome orders, which have been more effective in slowing transmission once it was too late for a containment strategy to be tenable. High attack rates and explosiveness (multiple cases appearing in a short time span) make it hard to stay ahead of a disease. These characteristics are functions of a disease's infectiousness and contagiousness: its ability to spread from person to person. COVID-19 is transmitted by respiratory droplets and aerosols produced when an infected person coughs or sneezes. This has led to COVID-19 having a daunting rate of transmission, with early estimates of a basic reproductive rate of between 4 and 9 (Sanche et al., 2020). ${ }^{12}$ As a point of reference, these transmission numbers are akin to those seen for past SARS, polio, mumps, yellow fever, and 1918 influenza outbreaks (see Figure 2). The economic history of these pandemics thus provides a guide for what we might expect from COVID-19. For contrast, the economic history of measles - which presents far higher transmission rates, with estimates of basic reproductive rates greater than 10 (Guerra et al., 2017)—offers a sense of how much worse things could be.

Figure 2: Case fatality rate as a percentage by basic reproduction rate for various diseases

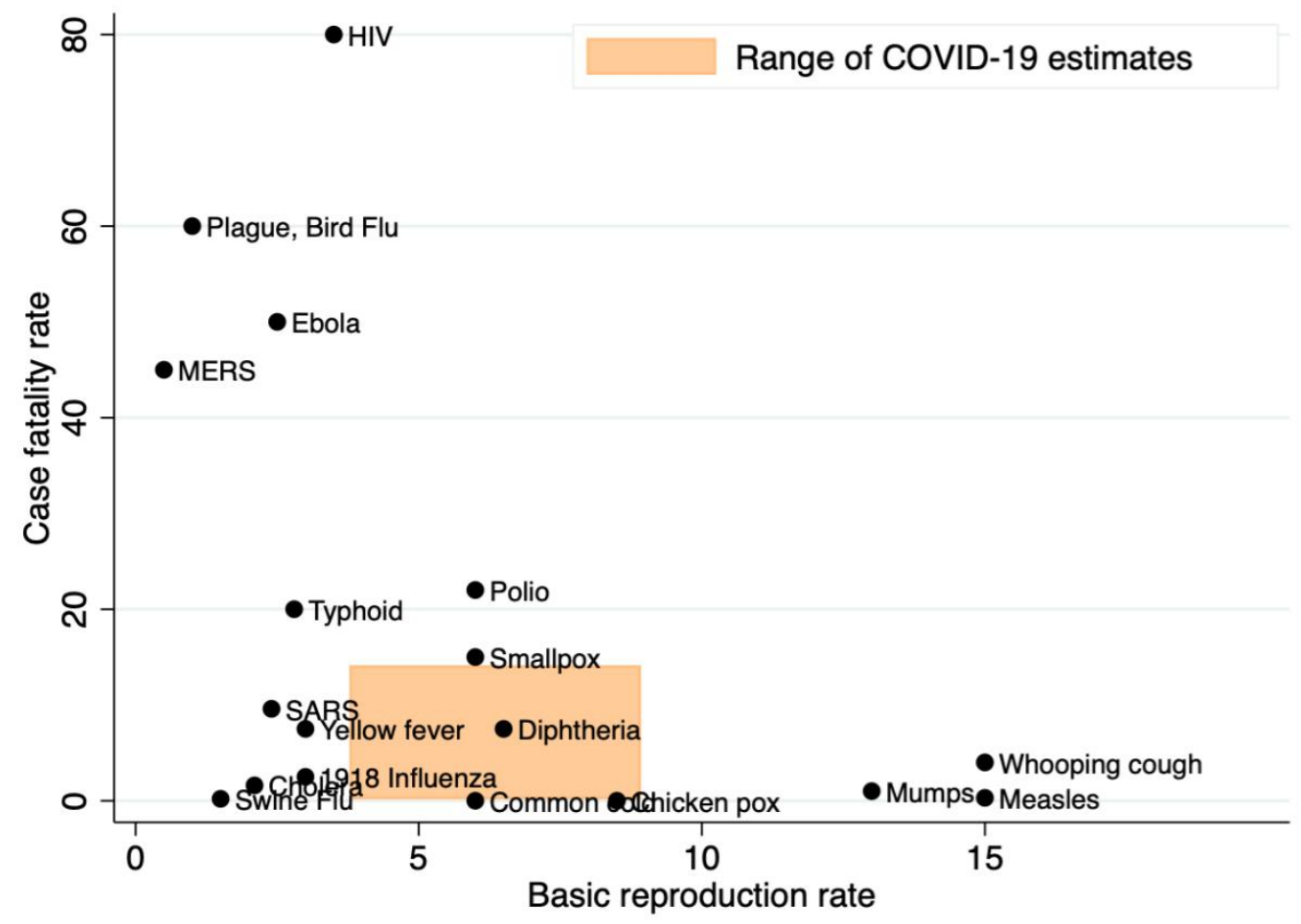

Notes: Case mortality rates are for untreated patients. For COVID-19, basic reproduction rates are taken from https://wwwnc.cdc.gov/eid/article/26/7/20-0282_article. All other reproduction and fatality rates are taken from https://docs.google.com/spreadsheets/d/1kHCEWYd9HXIWrft9jjRQ2xf6WHQlmwyrXel6wjxkW8/edit\#gid=0 (the data underlying https://www.theguardian.com/news/datablog/ng-interactive/2014/oct/15/visualised-how-ebolacompares-to-other-infectious-diseases), accessed on June 15, 2020.

\section{II.a.3. Pandemic Severity}

Like the disease's ease of transmission, the severity with which it manifests symptoms will also be a crucial determinant of both its consequences for individuals and the wider economy, and the nature and magnitude

${ }^{12}$ The basic reproductive rate is the number of expected cases directly generated by one case when all individuals in the population are susceptible to infection. 
of the government response. For instance, a highly lethal pandemic may generate extensive and indiscriminate mortality; a less lethal pandemic may generate culling (selective mortality related to a specific health threshold); and an even less lethal pandemic may generate very little mortality, but substantial health scarring among survivors. If a disease is so mild that many of those who are infected remain asymptomatic, this can, in the absence of widespread testing, undermine efforts to slow transmission. Likewise, rates of infection, in combination with severity considerations, will help determine whether governments intervene, or merely wait for the disease to "take its course" on the way to achieving herd immunity.

In its April 14, 2020 COVID-19 Strategy Update, the World Health Organization note that 40 percent of those infected experience moderate disease, including pneumonia, and 15 percent experience severe disease. They cite a crude clinical case fatality rate of over three percent that rises to 15 percent or higher in individuals over the age of 80. As shown in Figure 2, the crude mortality rate for COVID-19 in its first months is similar to that of the 1918 influenza pandemic and of measles, but far lower than the deadlier recent outbreaks of MERS, Ebola, SARS, and lower still than the truly devastating historical toll of smallpox, which had an average case fatality rate of 30 percent (Ellner, 1998).

This rich historical spectrum of pandemic severity, in turn, demonstrates that both mild and severe diseases impact the economy, albeit in very different ways. For instance, the eradication of hookworm in the U.S. South - a disease which is not fatal, but which primarily causes lethargy and anemia-improved returns to schooling, educational attainment, and incomes in areas with high prior infection rates, but did little to change to overall demographic, economic, or institutional structure (Bleakley, 2007). For contrast, the Black Death and other pre-modern outbreaks of plague, which had extraordinarily high death tolls, fundamentally reshaped the global economy through their effects on population size and demographic structure. ${ }^{14}$ In this context, COVID-19's wide scale and relative mildness will surely have a bearing on the scope, magnitude, and timescale of damages. As we will see in later sections, it suggests that we might ultimately expect to see the greatest harm only in the long run, with widespread generational scarring arising from short-run morbidity and economic disruptions.

\section{II.a.4. Population Immunity and Novelty}

The novelty of a pandemic virus contributes to its potential for destruction: it takes time to identify a new disease, understand key features of its epidemiology, develop treatments and vaccines, and achieve a degree of population immunity. In the meantime, everyone represents a potential victim. As a novel coronavirus, COVID19 struck a population with neither natural nor acquired immunity: wherever the virus spread, it had the potential to be devastating. With little immediate means of preventing, testing for, or treating it, the only short-run mitigation strategies available were relatively brute-force ones such as lockdowns and border closures. Consequently, economic shutdowns - resulting both from official government actions and from individuals taking actions to avoid exposure-were widespread, leaving no major economies or populations spared.

Interestingly, because medical technology was limited for much of the past, and societies could only count on some degree of population immunity, even endemic (i.e., non-novel) diseases could have the sort of destructive potential we only typically see today in new disease variants such as the novel coronavirus. ${ }^{15}$ For instance, in a

\footnotetext{
${ }^{14}$ Voigtländer \& Voth (2013a, 2013b) argue that the increased wages due to labor shortages from plague mortality increased demand for urban products, driving a cycle of urbanization and additional disease that moved Europe out of a Malthusian trap into a modern world of permanently higher per capita incomes. Dittmar \& Meisenzahl (2017) demonstrate that outbreaks of plague aided the spread of Reformation Laws and the expansion of public goods. For more on the economic history of plagues, see Alfani \& Murphy (2017).

${ }^{15}$ That is, it is improved medical knowledge that has allowed us to escape from the sort of flare-ups of endemic disease so frequently observed in the past, and it is relative our lack of knowledge about COVID-19, as a new virus, that makes our current situation in some ways comparable to even past endemic disease outbreaks. Economic historian Joel Mokyr
} 
variety of past pandemics studied by economic historians, cases of an endemic disease would sporadically rise sharply, with substantial consequences for living standards and economic organization. Indeed, a large literature considers the impact of such diseases on the growth trajectories of countries over the long run, often focusing on tropical diseases like malaria, yellow fever, dengue, and others. One strand of studies considers the direct impact of disease on human capital formation (see, for example, Bleakley $(2003,2010)$ on malaria). Another strand focuses on the impact of these endemic diseases on institutional development, finding that disease environments inhospitable to colonial settlers drove them to rely on extractive institutions that were ultimately harmful to economic growth (Acemoglu et al., 2001). Finally, scholars have considered the way that one society's acquired immunity to an endemic disease can devastate the economy of another society lacking that immunity (Diamond, 1999; McGuire \& Coelho, 2011; Tang, 2017).

Together, this historical evidence gives us a picture of what our circumstances might look like today if we are unable to adequately ramp up our capacity for disease prevention and treatment, and are instead forced to rely on acquired immunity, the nature of which for COVID-19 is still poorly understood.

\section{II.b. Demographics and Distributional Effects}

Age has been at the forefront of discussions about the disparate impact of the current crisis, and shutdown efforts have been framed in part around protecting older individuals and other vulnerable populations, such as the immunocompromised, while societies work to expand medical capacity and develop a vaccine. In this respect, COVID-19 is much like many infectious disease outbreaks in the past - the elderly and those with poor baseline health are at greatest risk. CDC estimates put the risk of hospitalization five times higher, and the risk of death from COVID-19 90 times higher, for 65 to 74 year-olds compared to individuals in their twenties. ${ }^{16}$

Likewise, despite claims in some quarters that COVID-19 is "the great equalizer," it is already becoming clear that socioeconomic status will be central to understanding the demographics of this crisis. One of the ways low-income populations will be affected is through differential exposure to pandemic risks. ${ }^{17}$ Individuals who continue to do their jobs in person during the pandemic - including service-industry workers with extensive contact with customers, healthcare professionals, and other frontline workers - will bear a disproportionate burden of the pandemic's health impacts. These workers are more likely to be in low-paying jobs, and are more likely to be women and minorities, than their counterparts with jobs allowing them to work from home. Consider, for instance, meat and poultry workers in the U.S. The mean annual wage in the industry is only $\$ 28,000$ (BLS, 2018). ${ }^{18}$ Among laborers in the food manufacturing industry, 27 percent are black and 40 percent are Hispanic (EEOC, 2018). ${ }^{19}$ Three-quarters of full-time, year-round healthcare workers are female, with that share even higher among the lower paid nursing and health aide occupations, critical occupations with severe risk of exposure to COVID-19. ${ }^{20}$ This disproportionate exposure to virus for lower income groups, women, and minorities is exacerbated by differences in these groups' access to healthcare and the quality of that health care - factors that affect both vulnerability and resilience to pandemic disease. Membership in more than one of these groups will tend to compound disadvantage even further. Preliminary research suggests that black patients exhibiting COVID-19 symptoms were six times less likely to get treatment or testing than

expands on this idea regarding the evolution of knowledge regarding infectious disease outbreaks in a recent op-ed: https://www.cnn.com/2020/04/23/opinions/struggle-between-people-and-microscopic-pathogens-mokyr/index.html.

${ }^{16}$ Retrieved from https://www.cdc.gov/coronavirus/2019-ncov/covid-data/investigations-discovery/hospitalizationdeath-by-age.html, August 25, 2020.

${ }^{17}$ The mirror image of differential exposure is differential transmission risk. This is one reason why some have called for prioritizing the strategic testing of workers at highest risk of spreading the novel coronavirus to others, particularly asymptomatic ones.

${ }^{18} \mathrm{https} / / / \mathrm{www}$. bls.gov/oes/2018/may/oes513022.htm

${ }^{19} \mathrm{https} / / / \mathrm{www}$. eeoc.gov/statistics/employment/jobpatterns/eeo1/2018/national-naics3/table?naics=311\&state=\&cbsa=

20 Figures are based on the U.S. Census Bureau's calculations using American Community Survey data (https://www.census.gov/library/stories/2019/08/your-health-care-in-womens-hands.html). 
white patients. ${ }^{21}$ This is not unique to COVID-19: similar patterns have been observed for other modern pandemics including the H1N1 influenza outbreaks (Quinn et al., 2011).

The outsized impact of pandemics on minority populations and people of lower socioeconomic status has historical precedent. ${ }^{22}$ The 1918 influenza pandemic hit the poor first and hardest (Sydenstricker, 1931; Mamelund, 2018), a point we will return to in Section III. Explanations for this relationship mirror modern ones: poorer populations lived in denser housing units under worse conditions, and had occupations that increased exposure to the virus. ${ }^{23}$ Moreover, low incomes constrained their ability to avoid exposure and seek treatment. ${ }^{24}$ Historical evidence shows that to escape a $19^{\text {th }}$ century outbreak of yellow fever, wealthier residents often left the city-an option unavailable to low-income workers with tenuous job security. This is a pattern that we see as well during outbreaks of plague in earlier centuries, and is part of Dittmar \& Meisenzahl's (2017) explanation for why the Black Death paved the way for institutional reform: the old elites simply left town (Dinges, 1995; Isenmann, 2014).

This sort of regional flight is unlikely to be a central dimension along which COVID-19 has differential impacts across income levels - but it does raise important issues that set the current crisis somewhat apart from other historical pandemics: the spatial distribution of population within and across cities, the degree of interconnection between rural and urban areas, and the extent of urban health penalties. While cities are much healthier today than in the past, ${ }^{25}$ societies today are also much denser, more urbanized, and better connected - all factors that would tend to make modern pandemics both faster to spread and harder to control than in centuries prior. And indeed, while COVID-19 has hit dense metropolitan areas particularly hard, as in the past, under the current crisis, rural communities have not been spared. This is in part because of the relative ease with which people circulate between communities with our modern transportation networks, but also because of the way that the nature of modern work tends to place individuals in close contact with each other, even in less densely populated areas. To wit, major rural clusters of COVID-19 in the United States have been tied to large meat and poultry processing facilities, with workers at these facilities experiencing case rates an order of magnitude higher than the general U.S. population (Dyal et al., 2020).

To respond effectively to pandemics in the moment, and to deal with their long-run fallout, will require an understanding of its distributional effects over time and space. We explore these central consideration in depth in Section III.

${ }^{21} \mathrm{https}$ //www.nytimes.com/2020/05/10/us/coronavirus-african-americans-bias.html

22 The relationship between pandemic exposure and socioeconomic status has not always been constant. As Alfani \& Murphy (2017) note, studies of the plague in Europe find the Black Death to have been universally deadly. However, plagues of the fifteenth and sixteenth centuries exhibited the negative relationship between socioeconomic status and mortality found in more recent pandemics (see, for example, Slack (1985), Alfani (2013), and Carmichael (2014)). However, the final major plagues of the seventeenth century once again tended to have severe consequences across all classes.

${ }^{23}$ Mamelund (2018) note that in Norway, the impacts of the pandemic were most severe for transport, hotel and industry workers, paralleling the observations above about COVID-19.

24 These factors also translated into worse outcomes for minorities. As the exception that proves the rule, black Americans fared better than white Americans during the 1918 pandemic (Crosby, 2003; Økland \& Mamelund, 2019). Crosby (2003) argues that the black population had disproportionately high exposure to the early, less virulent summer wave of the pandemic due to their worse occupations and living conditions, conferring some degree of immunity to the more deadly later wave. A similar mechanism operated during historical yellow fever outbreaks, albeit resulting in advantages for native-born individuals over immigrants. Individuals born in an area with endemic yellow fever and exposed at a young age often contracted a mild form of the disease, and then developed immunity. As a consequence, adult immigrants were far more likely to die in yellow fever outbreaks in the United States than either native-born whites or blacks (Patterson, 1992). Saavedra (2017) exploits this pattern to demonstrate that early-life yellow fever exposure negatively impacted adult occupational outcomes, with white males born to immigrant mothers during yellow fever pandemics less likely to become professionals than the sons of native-born mothers.

${ }^{25}$ This is thanks, for instance, to pollution regulation, improvements in public health and medical technology, and the rise of cities as centers of high-skilled and high-income workers, often with well-resourced healthcare facilities. 


\section{II.c. Policy Response}

Evaluating the policy response to COVID-19 and how it compares to historical pandemics requires recognizing that information on the disease and how to stop its spread has been limited to date, and is still evolving. ${ }^{27}$ This issue stems in part from COVID-19 being a novel disease-developing treatments and vaccines takes time, and public health recommendations can change as knowledge advances. It also stems from incomplete and inaccurate data: limitations on COVID-19 testing has often meant relying on mortality rates rather than case rates. Incidentally, this is the same approach economic historians are often required to take. Morbidity data are rare historically and, when available, may be unrepresentative and inaccurate. Mortality data are both far more prevalent and reliable, even if it is morbidity that is typically more relevant to the economic impacts of a pandemic, particularly less lethal ones. For health officials today, the need to assess the spread of COVID-19 through mortality data leads to the frustration of identifying the arrival of cases with a substantial lag. For the economic historian, this lag is irrelevant, but the issue remains that only those places experiencing excess mortality can be identified; diseases leading to widespread morbidity but little mortality may be equally important for the evolution of economies, but far more difficult to identify prior to modern medical records. Again, this suggests that evidence from crises that have run their course can be informative of what to expect going forward.

While some of the challenges in developing effective COVID-control responses have stemmed from incomplete and rapidly evolving knowledge of the disease, they have also stemmed from issues of state capacity, political will, and ideology. For instance, policymakers, firms, and individuals have been hamstrung by not only limited testing and contact tracing capacity, but also by a failure at times to deploy these tools in an efficient manner. Constraints such as these are a product of both the limitations of medical technology, and broader issues of political leadership and coordination. The inability to identify and isolate individuals at risk of spreading the disease, in turn, has necessitated rather blunt policy tools, such as business closures and stay-at-home orders. In the U.S. in particular, these COVID-control efforts have been aggressively decentralized, and have tended to prioritize both commerce and individual liberty - even where these might be at odds with each other, or lead to ineffective disease control. ${ }^{28}$ To wit, business owners and public officials have struggled to gain widespread compliance with (and have often declined to enforce) precisely the sorts of behaviors - e.g., mask-wearing, social distancing - that would allow for the safe reopening of businesses. Indeed, it appears that the fear and uncertainty created by the failure to control the spread of disease, in turn, has contributed to prolonging economic pain (Goolsbee \& Syverson, 2020). Challenges such as these, related to culture and institutions, are nothing new - in fact, they characterize the U.S.'s historical experience of managing epidemic disease. In his excellent The Pox of Liberty, Troesken (2015) lays out how the very institutional features - among them a decentralized federal system, a focus on property rights and commerce, and protection of individual liberties - that led to the U.S.'s rapid economic development also often undermined its attempts to control past outbreaks of smallpox, typhoid, and yellow fever. The examples he provides have uncanny parallels to the U.S.'s approach to managing COVID-19.

Strategies to manage the spread of COVID-19 have been varied, with many jurisdictions pursuing multiple complementary approaches, often including coordinated sourcing and distribution of protective equipment, reallocation of medical capacity, virus and antibody testing, contact tracing, frequent sanitizing of public

\footnotetext{
${ }^{27}$ In this section, we focus on policy attempts to control the disease, rather than policy interventions specifically aimed at addressing the economic fallout. Of course, the two are interrelated, and the latter have historical analogues as well, particularly in New Deal-era and post-Great Recession relief policies.

${ }^{28}$ Other countries offer a contrast on one or more of these dimensions. For example, taking a more authoritarian and centralized approach, China and India had some early success in containing the virus following swift and complete lockdowns, underscoring the potential importance of state capacity and centralization in pandemic control. Likewise, South Korea's response demonstrated the importance of relative novelty: due in part to experience with past respiratory pandemics, pre-existing public health infrastructure and greater public buy-in with mask-wearing allowed them to respond more quickly and effectively to COVID-19.
} 
facilities, social distancing, mask-wearing, managing congestion in public places by staggering timings and moving activities outdoors, limiting large gatherings, quarantining infected individuals, and minimizing risk of exposure via school and business closures and broader stay-at-home orders. Of these strategies, shutdowns and quarantines have been some of the most accessible, widely used, and hotly debated under COVID-19. A shutdown-centered approach such as this also has strong historical precedent. In fact, closures and quarantines were some of the only tools available to societies prior to the virology advances of the 19th and 20th centuries. Though the shutdown of firms has been more comprehensive under COVID19 than in many past pandemics, ${ }^{29}$ the primary measures being taken now, such as quarantining sick individuals, restricting public gatherings, and closing schools, were all implemented during the 1918 pandemic (Markel et al., 2007; Hatchett et al., 2007). Likewise, when England was combatting the plague in the 1600s, they quarantined ships from other countries, closed ale houses, and limited the number of lodgers allowed in a house, actions that would sound familiar to cruise ship passengers and restaurant owners during the COVID-19 pandemic (Bell, 1924). Indeed, it is striking - maybe even alarming - how little has changed about our best options for fighting pandemics, despite centuries of advances in medicine, public health, and living standards. This policy response, necessitated by inadequate testing and broader uncertainty about key epidemiological parameters - even those as basic as precisely how and through whom the disease can be transmitted, and whether it is possible to become re-infected-makes the economic history of policy responses to pandemics particularly relevant for studying the current crisis. ${ }^{30}$

Even when we contemplate a world where successful COVID-19 vaccines are available, history sounds a note of caution: the same underlying issues that have made mask-wearing both incomplete and fraught in settings, like the U.S., with a strong institutional commitment to liberty and rugged individualism, could also be expected in the context of COVID-19 vaccination. As Troesken (2015) notes, anti-vaccinationism has a long history in the U.S., bolstered by the common failure to appreciate the extent of infectious-disease externalities (the choice not to vaccinate can be individually rational, even if people understood externalities, which they largely do not), as well as by a belief in both minority rights (individuals cannot be forced to vaccinate) and federalism (individuals preferring not to vaccinate can sort into amenable jurisdictions). While Troesken documents that mandatory vaccination was frequently enforced in the past via fines, ${ }^{31}$ or by denying access to schools or other public services, it is difficult based on the nature of the U.S. COVID-19 response to date to imagine such enforcement mechanisms being implemented. Instead, in heterogeneous, strongly pro-individual, pro-freedom societies, we may need to rely on a stylized fact that Troesken demonstrates using data from $19^{\text {th }}$ century smallpox epidemics in Germany: vaccinations rates rise in pandemic years, because during pandemics, the risk of infection rises sharply, and the private costs of non-vaccination are clearly outweighed by the private benefits.

\section{Consequences for Wellbeing through the Health Channel: The 1918 Influenza Pandemic}

For thinking about the direct effects of pandemics on the health and wellbeing of individuals in the short-

\footnotetext{
${ }^{29}$ The greater use of firm closures as a disease-control strategy today could be due, for instance, to improvements over time both in the safety net and in remote-work capabilities. This more widespread pause on non-essential activities may in turn lead to fairly different effects of COVID-19 relative to past pandemics, e.g., in terms of patterns of disease transmission or total economic impact.

${ }^{30}$ See for example Markel (et al., 2007) on the effectiveness of school closures in combatting the spread of the 1918 influenza pandemic, Meyers and Thomasson (2017) on the effects of polio-related school closures on educational attainment, and Alfani \& Murphy (2017) on city-level quarantines during pre-modern plagues.

${ }^{31}$ Troesken (2015) notes that the underlying legal theory behind vaccination non-compliance fines gained further credence after the Supreme Court upheld the Affordable Care Act's insurance mandate in National Federation of Independent Business v. Sebelius, 567 U.S. 519 (2012).
} 
and long-run, the 1918 Influenza Pandemic, or the "Spanish Flu," provides a useful point of reference. COVID-19 to date parallels the 1918 pandemic in several key ways, including its rate of transmission, global spread, and crude mortality rates. ${ }^{34}$ The Spanish Flu was one of the most acute and widespread natural disasters in modern history. Taubenberger \& Morens (2006) estimate that during the pandemic, roughly 500 million individuals, equivalent to roughly a third of the world's population at the time, were infected and symptomatic. Case fatality rates, at over 2.5 percent, were at least 25 times as high as in other influenza pandemics, making the 1918 virus especially lethal. All told, somewhere between 50 and 100 million individuals perished globally. The death toll in the U.S. alone exceeded that from all American combat deaths over the twentieth century (Almond, 2006).

The pandemic itself was sharp, sudden, and concentrated over the span of little more than a 12-month period. The virus, an H1N1 strain similar to that which caused the 2009 swine flu outbreak, spread roughly simultaneously across Europe, Asia, and North America, in three distinct waves over the year beginning in spring 1918. The first of these waves, appearing in March 1918, was relatively mild. It was followed by a substantially more catastrophic one from September to November 1918, and another in the early months of 1919 (Taubenberger \& Morens, 2006). In some parts of the world, particularly in East Asia, a further major wave of pandemic influenza hit as late as 1920 (Lin \& Liu, 2014; Ogasawara, 2018).

This sort of timing and spacing was unprecedented among influenza pandemics, as was its distinctive mortality profile. Where influenza death rates by age typically follow a U-shape, with high mortality rates among the very young and the very old (as is also the case with the SARS-CoV-2, the virus behind COVID19), the 1918 strain followed a W-shape, with a sharp peak in mortality risk among young adults as well. ${ }^{35}$ Indeed, almost half of all influenza-related deaths during the pandemic period accrued to those aged 20-40 (Taubenberger \& Morens, 2006).

The age pattern associated with this strain of influenza was in fact so unusual that it has been exploited as a diagnostic tool in recent studies. For instance, while the 1918 influenza pandemic is typically thought to have emerged in full force in Europe around the summer of 1918, and in a milder form somewhere in the central U.S. in spring 1918, detailed age-by-month mortality statistics allow Olson et al. (2005) to uncover evidence that an early "herald" wave of pandemic influenza was actually present in New York City well beforehand, from February to April of 1918. During this period, the age profile of excess influenza mortality had started to shift from the older ages typical of interpandemic seasons to the younger ages that characterize pandemic seasons. This underscores the value of accurate and disaggregated data in tracing the origins and spatiotemporal spread of pandemics, and the need to strengthen not only rapid-response public health infrastructure, but also that to support ongoing disease surveillance.

Turning to morbidity, those under the age of 35, and particularly, those aged 5-14, had disproportionately high incidence of influenza - however, the latter group had a much lower death rate from influenza and pneumonia than other ages, further sharpening the middle peak in the morbidity-adjusted pandemic mortality curve (Taubenberger \& Morens, 2006). Age, however, was not the only major factor that contributed to pandemic mortality risk, and a range of recent studies have emerged cataloging the often interrelated features of countries, cities, and individuals that led to disparities in the immediate mortality burden of the 1918 flu.

\section{III.a. Short-Run Mortality Effects \& Mechanisms}

On these mechanisms, the evidence is mixed-surely in part because of diverse empirical settings and

\footnotetext{
${ }^{34}$ There are challenges to drawing lessons from the 1918 pandemic. Much remains unknown about the origins and epidemiology of the virus and its economic impacts are confounded by the effect of World War I.

${ }^{35}$ Case fatality rates also followed a striking W-shaped pattern, contrary to the typical U-shaped pattern in this metric.
} 
disciplinary approaches — but certain patterns do emerge.

First, baseline health status mattered: both pre-pandemic pneumonia, a bacterial condition with a strong biological interaction with the influenza virus, and infant mortality rates, a proxy for population health, contributed to higher pandemic flu mortality (Acuna-Soto et al., 2011; Clay et al., 2019). Likewise, high levels of air pollution, an environmental factor that aggravates respiratory conditions and depresses baseline health, also raised pandemic mortality. For instance, Clay et al. (2019) examine evidence from a panel of 438 U.S. cities, and find that the air pollution generated by coal-fired electricity plants was a significant contributor to pandemic mortality, with effect sizes roughly half those associated with measures of population health and poverty. ${ }^{36}$ Together, they estimate that these factors accounted for approximately half of all cross-city variation in pandemic mortality. In another study, they find that both infant and all-age mortality were impacted adversely by the presence of coal-burning plants, with poor air quality responsible for 19-26 percent of total pandemic mortality in high- and medium-pollution cities, a figure equivalent to some 30,000-42,000 excess deaths beyond those attributable to the pandemic alone (Clay et al., 2018). ${ }^{37,38}$

Second, population density and related concerns, such as housing quality and the number and composition of social interactions, were also important factors in pandemic mortality. In Europe as in the U.S., the pandemic came to cities earlier, and was more devastating there, a phenomenon linked to urbanization and residential crowding (Chowell et al., 2008; Mamelund, 2006; Murray et al., 2006). Transmission was localized, and influenza and pneumonia mortality exhibited significant and rather tight (e.g., 200-1,500 m) spatiotemporal clustering (Grantz et al., 2016a,b; Tuckel et al. 2006), though proximity to high-risk population centers like WWI military bases appears to have had little effect (Clay et al., 2019). Although urban centers were associated with higher pandemic mortality, the opposite population gradient prevailed when comparing among cities, or among rural areas: in both cases, smaller, less dense localities fared worse (Acuna-Soto et al., 2011; Chowell et al., 2008), suggestive perhaps of capacity constraints in the healthcare workforce and medical infrastructure.

Third, factors - such as illiteracy and foreign-born status - that might have prevented individuals from adopting public health recommendations were strong predictors of elevated mortality, often above and beyond their association with poverty. ${ }^{39}$ Higher rates of illiteracy were linked to higher rates of influenza mortality during the pandemic, across both cities and neighborhoods (Clay et al., 2019; Grantz et al., 2016a, b). Likewise, foreign-born status not only predicted higher pandemic mortality in Hartford, CT, but the

\footnotetext{
${ }^{36}$ It is possible that indoor pollution and seasonality also played a role in air quality-influenza interactions, both during and outside pandemic times. For instance, influenza is generally prevalent in the winter, a time when coal smoke from home heating also tended to peak in this era (Barreca et al., 2014).

${ }^{37}$ Clay et al.'s (2018) observation that modern levels of pollution in parts of the developing world, including India and China, are on par with those in the early $20^{\text {th }}$ century U.S., sounds an ominous note in light of the current crisisthough the circumstances today (e.g., improved medical technology, the higher baseline share of traffic-related emissions, a fall in pollution due to widespread economic shutdowns) may be just different enough to ameliorate concerns over the lethal interaction between pollution and pandemic influenza.

${ }^{38}$ While pollution can lower baseline health by undermining the respiratory system, it is worth noting that pollution may also be associated with higher baseline health, insofar as it proxies economic activity. For instance, Clay et al. (2016) find evidence of crucial tradeoffs between the income generated through industrial activity on the one hand, and the pollution generated on the other in the U.S. from the 1930s to the 1960s. In less developed localities, infant mortality followed a U-shaped pattern with respect to the expansion of coal capacity: first falling as rising incomes and cleaner residential energy sources buoyed infant health, and then rising as subsistence health needs were met and the concentration of pollution grew. The net health effects of a pandemic that dampens economic activity (and so reduces pollution), then, is therefore likely to be context-specific, depending on factors such as the level of baseline health and income, the extent of medical infrastructure, and the strength of social safety nets.

${ }^{39}$ Troesken (2015) also points to individualism and liberty as cultural/institutional values that tend to lower individuallevel compliance with public health recommendations.
} 
relationship between nativity and mortality persisted even after controlling for socioeconomic status, population density, and neighborhood ethnic composition, indicating perhaps a role for social factors, or language or cultural barriers to the adoption of relevant public health measures (Tuckel et al., 2006). Crucially, the consequences of these barriers were not limited to the foreign-born: holding all else equal, native-born individuals living in areas with a higher share of foreign-born had higher mortality rates than their counterparts living alongside a lower share of foreign-born neighbors. This emphasizes the importance of neighborhood spillovers in infectious disease transmission - and, of course, demonstrates the interrelated nature of individual- and neighborhood-level mechanisms.

When considering these biological, demographic, and socioeconomic factors in quick succession, it is difficult not to see the overarching hand of income in all of these mechanisms - though, to be clear, several of these studies are careful to disentangle these factors from their association with income. In theory, income gradients in pandemic mortality could arise through a number of channels, including many of those hinted at above: e.g., the tendency of those with higher incomes to have better baseline health status, rendering them biologically less vulnerable and more resilient to infection; higher-quality and lower-density housing, reducing the chances of viral transmission; better public health knowledge, the human capital necessary for individuals to effectively assimilate this knowledge and to adopt life-saving recommendations, and timelier and more robust public health interventions, all slowing the spread of illness; better access to healthcare and medical infrastructure, improving the probability of survival conditional on infection; and a greater capacity for individuals to undertake avoidant, adaptive, and compensatory behaviors, both throughout and following the pandemic. Crucially, these channels can operate at both individual and institutional (e.g., city or country) levels, with both richer people and localities - and certainly, the interaction of thesetheoretically better equipped to weather the crisis. The fact that some of these channels are highly correlated, of course, can make it difficult to pinpoint the underlying mechanisms: higher-socioeconomic status (SES) individuals are likelier to be both healthier, protecting them from infection, and more educated, rendering them better able to adopt public health measures; cities tend to be richer in both income and infrastructure, but they are also more heterogeneous and densely populated than rural areas.

Nevertheless, the literature can still shed light on the role of income on net. While some studies explicitly looking at its role in pandemic severity have shown little relationship between pre-1918 economic development and pandemic mortality (Brainerd \& Siegler, 2003), a great many indicate that poverty exacerbated mortality risk. For instance, Murray et al. (2006) document tremendous (i.e., over thirty-fold) within- and cross-country variation in excess mortality due to the 1918 pandemic, with nearly half of this variation explained by baseline per capita income. Taking a finer-grained look at these issues, Grantz et al. (2016a,b) explore the socioeconomic determinants of pandemic mortality and transmissibility using detailed data from Chicago. Among the associations they find between health and various poverty proxies are large, statistically significant, and negative associations between census tract-level homeownership rates and mortality. These findings are consistent with the lower baseline health of lower-SES neighborhoods, their poorer access to medical care, and their lower awareness and adoption of public health recommendations. Shanks \& Brundage (2017) add that these factors may be proxying other features of low-SES populations, such as a higher risk of sequential infections (e.g., pandemic influenza followed by a secondary bacterial infection such as pneumonia), or the larger number and lower-SES composition of their social interactions. All of these could have contributed to higher cumulative pandemic mortality through faster and more widespread disease transmission, higher incidence of infection, or higher case fatality rates. These results suggest that rather than acting as a democratizing force, the pandemic further entrenched preexisting socioeconomic disparities. The clear implication of studies documenting the immediate health effects of the 1918 outbreak is that the damage from pandemics has, and remains likely to, fall disproportionately on poor communities.

\section{III.b. Demographic Effects}

Apart from its effects on health, however, the pandemic also had important consequences for population 
dynamics. One such effect pertains to temporal and cross-disease mortality spillovers resulting from pandemic-era mortality patterns. Noymer (2011) shows that the 1918 influenza pandemic hastened the decline of tuberculosis in the U.S. through a harvesting mechanism. Specifically, he suggests that independent competing risks may be responsible for this phenomenon, driven by substantial age overlap in the profile of prospective tuberculosis and (pandemic-type) influenza victims. This "passive selection" contrasts with "active selection" based on biological interactions between influenza and tuberculosis. This harvesting, in turn, had long-lived implications for sex differences in post-pandemic mortality rates: because tuberculosis morbidity disproportionately affects men, and because the influenza pandemic reduced the pool of those who might die of tuberculosis in the years following, the pandemic had the effect of eroding women's longevity advantage over men. We might expect similar outcomes in the context of COVID-19 given that a large share of those dying have one or more co-morbidities, though the distinct age profile of 1918 pandemic deaths versus COVID-19 deaths may complicate these dynamics. Studying Brazil, Guimbeau et al. (2020) likewise find rather larger reductions in sex ratios at birth following the 1918 influenza pandemic, consistent with the greater vulnerability of male fetuses to adverse in utero shocks-a phenomenon often seen in the literature on famines and environmental disasters. Such changes in the sex ratio, or in sex-specific survival, may well have had long-run implications for marriage and labor markets.

Another major area in which the pandemic affected demographic behavior relates to marriage and fertility. In some cases, this was largely a function of pandemic psychology. Mamelund (2004) shows that a climate of fear and uncertainty in 1918 Norway, alongside social distancing efforts and peculiarities of Norwegian marriage laws (which imposed a one-year waiting period before widows could remarry), led to a drop in births in 1919, as families deferred childbearing. Higher rates of maternal mortality and miscarriage during the pandemic likely also contributed to a drop in birth rates. This pent-up demand for children (alongside "replacement" demand for children lost to the pandemic) was released after the crisis passed, resulting in a baby boom in 1920. Elsewhere, as was the case in nearby Sweden, changes in fertility arose from the way that pandemic mortality affected markets for marriage and labor: Boberg-Fazlić et al. (2017) find evidence of a drop in fertility during the pandemic, followed by a short-lived rebound in post-pandemic fertility. The net effect in the long term, however, was to reduce fertility — due in part to persistent disruptions to marriage markets (particularly in rural areas and poorer cities); the adverse effects on income; as well as to behavioral changes induced by the pandemic, including a rise in female labor supply (and so, an increase in the opportunity cost of childrearing) in regions with high male pandemic mortality rates. Perhaps most noteworthy, the short-run post-pandemic fertility increase was selective in nature: a child born during this boom was more likely born to mothers who were married or who were high-SES city-dwellers. This was largely driven by postponement fertility, and particularly, selective postponement. ${ }^{40}$ Finally, pandemicrelated mortality affected childbearing through its effect on survivors' incomes. Donaldson and Keniston (2014) show that the high pandemic death toll in some regions of India implied a substantial increase in per capita incomes, as survivors assumed the agricultural land of pandemic victims. In light of this rise in incomes, they find an increase in both the quantity and quality (given by literacy and height) of children born following the pandemic in India. Phenomena such as these, which change the sex- and agecomposition of the population - not to mention the average health status of successive cohorts - are likely to have long-lived effects on economic development, population health, and individual wellbeing.

\section{III.c. Long-Run Effects}

The lethality and peculiar age profile of the 1918 pandemic also give rise to long-run considerations. These may be especially relevant in light of COVID-19, where the vast majority of people who become sick ultimately survive. ${ }^{41}$ During the 1918 pandemic, young adults - including prime childbearing-age women-

\footnotetext{
${ }^{40}$ Across settings, evidence of replacement fertility is rather more limited.

${ }^{41}$ Note however that COVID-19 appears to be less prevalent, and possibly less severe, among prime-aged people. Consequently, it is possible that scarring through the health channel under COVID-19 may end up being less severe, and/or less widespread, than that following the 1918 influenza pandemic. Scarring through the income/labor-market
} 
were some of the likeliest to fall ill: in some parts of the U.S., roughly a third of all mothers (relative the about 28 percent of the general population) became infected during the crisis (Almond, 2006). Moreover, despite the unprecedentedly high mortality rates from this pandemic, most of those infected ultimately survived. This left considerable scope for maternal morbidity - and, through the impact of maternal stress and illness on intrauterine hormones, nutritional resources, and other factors - for insults to fetal health. ${ }^{42}$

In what is perhaps the seminal study in economics of the 1918 influenza pandemic's long-run effects on wellbeing, Almond (2006) finds wide-ranging adverse effects on later-life human capital and labor market outcomes among U.S. cohorts exposed to the pandemic in utero. These include substantial reductions in high school completion rates, wages, and socioeconomic status, alongside large increases in the probability of living in poverty, the receipt of welfare payments, the likelihood of incarceration, and-particularly among men - the probability of physical disability. That these adverse outcomes exist in spite of a pandemic-induced increase in miscarriages, stillbirths, and infant mortality rates (see, e.g., Guimbeau et al., 2020; Mamelund, 2004) - all culling forces which likely resulted in a pool of survivors if anything positively selected on health-is a testament to the catastrophic extent of pandemic scarring.

Almond's initial study has also since spawned a large and varied literature interrogating the long-run effects of the 1918 pandemic across a range of empirical settings. A first set of studies dig deeper into the U.S. case. One such study shows that 1919 birth cohorts (and in particular, those born in Quarter 2 of 1919, who were in utero at the height of the pandemic), are 4 percentage points (or 10 percent) more likely to report fair or poor health than their counterparts born in surrounding years; see a statistically significant 17-35 percent increase in a range of functional limitations, including trouble hearing, speaking, lifting, and walking; and are also likelier to experience diabetes and stroke (Almond \& Mazumdar; 2005). Others debate the possibility of pandemic-induced selection into fertility, which could confound estimates of the long-run health effects of early-life pandemic exposure. These studies ultimately conclude that the positive selection of WWI recruits, and the corresponding negative selection of pandemic-era fathers, does not substantially alter the conclusion that fetal exposure to the 1918 pandemic was a major and direct cause of these cohorts' later-life disadvantage (Brown \& Thomas, 2018; Beach et al., 2018).

A newer set of papers, focusing on non-Western, and particularly, lower-income, settings, shows that the evidence on the pandemic's long-run penalties is robust across a range of empirical contexts, each with different levels of baseline income and health status, different institutional responses to the pandemic, and different degrees of involvement in WWI. For instance, as in the West, in Taiwan there is evidence of permanent scarring: cohorts exposed to the pandemic in utero faced penalties with respect to educational attainment, heights, kidney disease, circulatory and respiratory issues, and diabetes (Lin \& Liu, 2014). In low-income settings with minimal public health intervention, even higher incomes only did so much to buffer these shocks: in a sample of high-SES children in Japan, Ogasawara (2018) finds that in utero exposure to the 1918 influenza pandemic reduced boys' and girls' heights by $0.28 \mathrm{~cm}$ and $0.14 \mathrm{~cm}$, respectively - magnitudes which in other studies have been associated with substantial increases in the probability of type II diabetes, osteoarthritis, and heart disease. The long-run results seen in Japan, as in Guimbeau et al. (2020) in Brazil, are consistent with sex differences in resilience to adverse health shocks.

channel, however (explored in more detail in Section IV), could well be substantially worse following COVID-19 than the 1918 pandemic, given the latter's relatively mild and short-lived effects on the economy.

${ }^{42}$ Now quite common and influential in economic research, the conceptual framework linking early-life conditions to later-life health and wellbeing is termed the "Barker" or "fetal origins" hypothesis. This hypothesis holds that certain chronic conditions stem from deficits in the fetal environment (Barker, 1992). Based on this initial literature in epidemiology and medicine, which focused on evidence from historical famines, a growing literature in economics has used these ideas to model the technology of human capital formation, and to identify sensitive and critical periods for the development of a range of outcomes contributing to labor market success and general wellbeing, including cognitive and non-cognitive skills, metabolism, and longevity (Heckman, 2007; Almond \& Currie, 2011). 
The reduction in the health, human capital, and labor market prospects of cohorts exposed in utero also appears to have dampened their marriage market prospects in ways that continue to carry intergenerational consequences. While both men's and women's own educational attainment was lower among exposed cohorts, only exposed women appear to suffer a marriage market penalty: they marry earlier, to spouses with lower levels of education (Fletcher, 2018). These are factors generally understood to reduce household incomes, female control of household resources, and the budget share allocated to child-centric expenditure. As such, these effects could represent a mechanism - alongside, e.g., epigenetics, or the more direct role of parental education in facilitating children's access to quality healthcare and schooling - by which we see intergenerational persistence in the consequences of early-life exposure to the influenza pandemic of 1918. Indeed, moderate adverse effects on educational attainment, occupational prestige, and family socioeconomic status have been documented up to the third generation, i.e., the grandchildren of those exposed in utero (Cook et al. 2019).

What action, if any, did households take to shield their children from these effects, or to help them recover? While surprisingly little has been written in the context of the 1918 pandemic on questions of individualand household-level avoidance, adaptation, and remediation, Parman (2015) is a noteworthy exception. ${ }^{43}$ Drawing on linked microdata from the U.S., he finds evidence of reinforcing investments in response to the 1918 influenza pandemic: that is, families with a child in utero during the crisis shifted resources to the child's older siblings, leading the latter children to higher educational attainment. Parman explicitly rules out changes in family size, birth spacing, or selectivity in any such changes, underscoring that the effects observed here are directly a function of parents reallocating limited resources away from affected children, and toward the child with a higher human capital endowment at birth. Thus, household responses may have if anything compounded any early-life disadvantage associated with the 1918 shock.

\section{Consequences for Wellbeing through the Economic Disruption: The Great Depression \& Other Historical Downturns}

Historical pandemics can help us think about potential long-run effects on wellbeing arising directly through the current pandemic's patterns of morbidity and mortality. But what about the impacts resulting from its disruption of daily economic life? One of the central features of the current coronavirus pandemic is the sudden, extreme, and widespread economic disruption it has caused. On this count, it has perhaps less in common with other recent pandemics. Indeed, the immediate economic disruption caused by the 1918 pandemic pales in comparison to that caused by COVID- $19 .{ }^{44}$ So, while this historical pandemic can give

\footnotetext{
${ }^{43}$ Some work has, however, addressed the broader policy responses (and lack thereof) to the 1918 pandemic in the U.S. For instance, Hatchett et al. (2007) find that cities that simultaneously implemented multiple non-pharmaceutical interventions (consisting of, e.g., isolation of sick individuals, bans on public gatherings, mandatory notification of disease, and closure of public gathering places, staggered business hours, and no-crowding rules) early in the pandemic had peak mortality rates roughly half that of cities that did not implement such interventions, and substantially less-steep epidemic curves. No single intervention was responsible for these gains; rather, it was the combination of multiple mutually reinforcing interventions that were effective. These findings are in line with Markel et al. (2007), who emphasize the importance of early and sustained non-pharmaceutical interventions during the pandemic. While many cities were successful in taking such a multi-pronged approach to pandemic management, on the whole the U.S. policy response to the 1918 pandemic was rather weak, undermined by a preoccupation with World War I-related efforts.

${ }^{44}$ Until the COVID-19 crisis, there had been relatively little work on the effects of the 1918 pandemic on economic activity, largely for lack of high-frequency, spatially disaggregated data on local economic conditions (see Beach et al. (2020) for an excellent overview of both the state of this literature and related empirical challenges). Indeed, the precise magnitude and temporal reach of these economic effects are still being debated (see, e.g., Basco et al. (2020), Barro et al. (2020), Correia et al. (2020), Lilley et al. (2020), and Velde (2020)), and a challenge for many of these studies in identifying pandemic effects on the economy remains the confounding effect of World War I. Moreover, it
} 
us insight into long-run effects on wellbeing through the health channel ("direct" effects), we must look elsewhere to think about the long-run consequences of pandemics through corresponding economic downturns ("indirect" effects).

But where to look for a suitable comparison? In some ways, episodes such as the Black Death or the AIDS crisis in Sub-Saharan Africa would seem to present closer analogues than the 1918 influenza pandemic, as health events with massive and lasting economic ramifications. ${ }^{45}$ The catastrophic loss of life under these pandemics fundamentally reshaped entire societies and economies, with, for instance, the resulting labor scarcity driving up the real wages of survivors, and, in some cases, precipitating other major demographic, economic, social, cultural, and institutional changes (Young, 2005; Alfani \& Murphy, 2017). Indeed, some point to the former plague as a major contributor to sustained rises in Western European living standards even under a Malthusian regime (Voigtländer \& Voth, 2009, 2013a,b), and to the region's rapid economic development and eventual divergence from the rest of the world over the early modern period (Clark, 2007).

\section{Figure 3: Unemployment rate and COVID-19 cases in the U.S. by state over time}

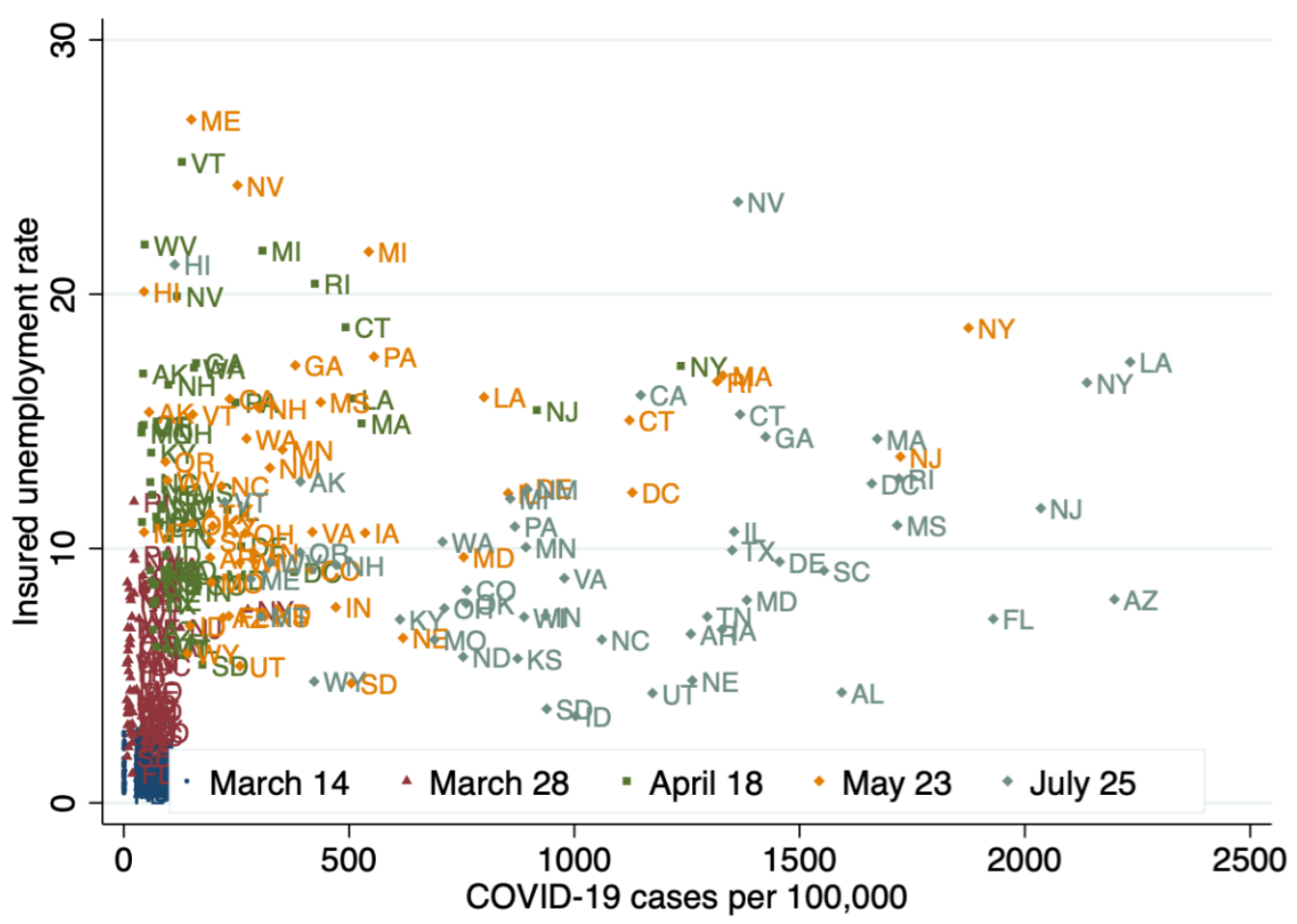

Notes: The insured unemployment rate is based on employees covered under unemployment insurance as reported to states by employers. COVID-19 cases are relative to the entire state population. Unemployment data were retrieved from https://oui.doleta.gov/unemploy/claims.asp. COVID-19 data were retrieved from https://github.com/nytimes/covid-19-data.

In each of these pandemics, mass mortality led to rapid and dramatic changes in population density and age structure, which in turn affected factor prices and labor markets. Thankfully, mortality rates under COVID-

is worth noting that the 1918-focused studies that have emerged in the wake of COVID-19 tend to conflate the economic effects of the pandemic that arise from within and outside the "direct health-shock" channel. To disentangle these channels and use a shock of comparable magnitude, we focus primarily on the Great Depression when examining the long-run human effects of economic dislocation.

${ }^{45}$ See Alfani \& Murphy (2017) for an excellent and in-depth review of the literature on pre-industrial plagues, their long-run socioeconomic consequences, and parallels to modern pandemic control efforts. 
19 are not on such a scale as to produce the sort of fallout seen with these events. ${ }^{47}$ Instead, it appears it may be a combination of factors other than the virus's actual toll on morbidity and mortality that is the source of economic dislocation in this instance. Indeed, as Figure 3 shows, the severity of the immediate health effects has not been a clear predictor of a locality's economic downturn. Likewise, emerging evidence complicates the popular conception that pandemic-control measures themselves, such as stay-at-home orders, are primarily responsible for the downturn associated with COVID-19. For instance, while Gupta et al. (2020) suggest that $60 \%$ of the decline in employment in the early months of the pandemic was driven by state and local social distancing policies, Kahn et al. (2020) show that the labor market effects of COVID-19 to date have been broader-based than is typically thought. All U.S. states exhibited a collapse in job vacancies in March 2020, and a corresponding rise in UI claims, irrespective of either the intensity of the virus's initial spread or the timing of stay-at-home orders. These phenomena were seen for the most part across both essential and nonessential sectors, directly- and indirectly-affected sectors, and across occupations with and without workfrom-home capabilities. They conclude that "the current damage done to the economy is not solely caused by the stay-at-home orders; it is too large and pervasive." Exploring the drivers of the collapse in economic activity, Goolsbee \& Syverson (2020) suggest that "individual choices were far more important [than government restrictions,] and seem tied to fears of infection." These voluntary disease-avoidance strategies by individuals are likely connected to the lack of decisive and coordinated policy responses, and to broader uncertainty about this novel disease. It remains to be seen whether other plausible mechanisms may also have a role-e.g., global supply chains that allow COVID-related firm slowdowns in one country or sector to propagate to others, or changes in firm production decisions under COVID uncertainty.

Clearly, both the current crisis and our understanding of it are still rapidly evolving. What we do know, however, is that the downturn this pandemic has precipitated is substantially larger than in other modern pandemics, and unlike in some pre-modern plagues, is likely unrelated to either mortality-related changes in demography or to reductions in labor supply or work capacity due to morbidity. As such, crises of primarily economic origin, such as historical recessions - and in particular, the Great Depression - may make the best analogues: while the coronavirus pandemic is a public health crisis, to be sure, it has manifested above all as a massive economic disruption, both in terms of magnitude and reach. ${ }^{49}$ Accordingly, we might want to think about its health and human capital consequences through this "livelihoods" channel as well. Indeed, it is these effects that are likely to be most relevant to our current situation.

\section{IV.a. Business Cycles and Health}

Beginning with short-term effects, we can look to a large literature on business cycles and health. These studies indicate that the net effects of downturns on morbidity and mortality will likely be highly contextdependent. This is because health is multidimensional, there are many countervailing channels through which local economic conditions can affect wellbeing, and because the particulars of the empirical settinge.g., the size, nature, and origin of the shock; the baseline level of population health; and the strength of social safety nets - will ultimately govern which of these effects dominate (Arthi et al., 2017; Cutler et al., 2016). Recessions have been shown to improve health, for instance, by freeing up time for health-promoting activities such as exercise, childcare, and breastfeeding (Dehejia \& Lleras-Muney, 2004; Miller \& Urdinola,

\footnotetext{
${ }^{47}$ Even while modern globalization has made disease transmission faster and harder to control, and even while increased efficiency in healthcare systems and global supply chains have complicated efforts to quickly ramp up treatment and control responses, other modern factors have made the current pandemic less dangerous to health than those that came before it - among them, improved medical technology, which has made it easier to manage secondary infections, and higher incomes, which have made human populations both less vulnerable and more resilient to infectious disease.

${ }^{49}$ This is certainly true at least in a distributional sense. While adverse effects will certainly be severe through direct morbidity/mortality channels, these will nevertheless be relatively concentrated. For contrast, adverse spillovers from these direct health effects, and from broader disease-control efforts, will be much more diffuse, even if less acute. Consider, for instance, that unlike the health-channel scarring effects of pandemics discussed in Section III, the economy-channel shocks apply to everyone to one extent or another, not just those who survive infection.
} 
2010; Ruhm, 2000); by reducing the income available to sustain unhealthy behaviors such as alcohol, tobacco, and drug abuse (Ruhm \& Black, 2002; Ruhm, 2005); by reallocating high-skilled but displaced healthcare workers toward higher-risk populations (Stevens et al., 2015); and by limiting individuals' exposure to environmental and work-related hazards, including traffic accidents, on-the-job injuries, and pollution (Muller, 1989; Chay \& Greenstone, 2003; Miller et al., 2009). ${ }^{50}$ Meanwhile, adverse income shocks can compromise access to basic needs such as nutrition, medical care, and housing (Griffith et al., 2013; Painter, 2010); and can cause psychological stress that in turn raises rates of self-harm and risky behaviors (Eliason \& Storrie, 2009; Sullivan \& von Wachter, 2009) ${ }^{51}$ While in theory, the net effect of local economic shocks on health is ambiguous, in practice, the bulk of the evidence drawn from modern and rich-country settings suggests that on net, total mortality rates fall during recessions (Arthi et al., 2017). In addition to setting-specific features like higher baseline health and stronger safety nets, the fact that beneficial channels tend to dominate in these settings may be in part because this evidence comes principally from small fluctuations in local economic conditions: using cross-country evidence over two centuries, Cutler et al. (2016) show that mild downturns lower mortality, while large ones raise it. ${ }^{52}$ The downturn caused by COVID-19 would surely qualify as the latter.

The evidence is much more mixed in developing-country and historical settings, where levels of baseline income and health are low, where safety nets are weak, and where cutting-edge medical technology is less accessible (see, e.g., Baird et al. (2011) and Ferreira \& Schady (2009)). In such settings, even small losses in income can be devastating to health (Costa, 2015; Heckman, 2007), and there is less scope for the sort of offsetting positive spillovers and behavioral changes seen in more modern and affluent settings. ${ }^{53}$ Consequently, this evidence seems to more often indicate countercyclical mortality. For instance, Arthi et al. (2020a) show that even in the presence of adaptive migratory responses, the Cotton Famine, a major 1860s downturn in Britain's cotton textile-producing regions, substantially raised mortality in cotton regions, particularly amongst the elderly (who were more sensitive to income shocks), amongst cotton households (who faced unemployment and reduced hours), and amongst those working in non-tradeables (whose livelihoods depended on the success of the local cotton industry). Diverse historical evidence such as this can help us think about how the effects of the COVID-19 crisis might out play out differently in other economies, particularly in the long run-something we cannot get from modern data, and especially, from modern U.S. data, alone.

\footnotetext{
${ }^{50}$ The case of pollution in particular underscores how complex the interactions between health and the economy can be-all the more so during a respiratory pandemic that has precipitated an economic crisis. Tied as pollution is to economic activity, a downturn that reduces pollution (and so reduces direct health hazards) also reduces income (and so raises indirect health hazards). Moreover, it does so unevenly across space and demographic groups. Add to this long-standing (i.e., baseline) distributional considerations around who is most exposed to environmental and pandemic hazards (see, e.g., Chay \& Greenstone, 2005; Currie et al., 2015); and who, conditional on exposure, is most sensitive to income shocks, environmental shocks, infectious disease shocks, or even all three simultaneously (see, e.g., Hsiang et al. 2019; Almond \& Currie, 2011); and a key question for assessing COVID-19's effects through economyenvironment interactions then becomes, from both an aggregate and distributional standpoint, whether and for whom the losses in health and human capital through the income channel are offset by the gains in health through actions taken to reduce the spread of influenza, the reduction of pollution, and the interaction of these factors.

${ }^{51}$ See Arthi et al. (2017) for a much more detailed review. Note as well that under COVID-19 stay-at-home orders and supply-chain disruptions, the effects through many of these mechanisms are likely to be much more extreme, since the reduction in economic activity has been much more acute (in some cases, nearly absolute).

${ }^{52}$ This is the case even in rich countries, but especially in poor ones. In the latter, as discussed above, even smaller economic fluctuations can raise net mortality.

${ }^{53}$ Consequently, we might expect developing countries to face the greatest tension between the desire to limit the direct health costs of COVID-19 on the one hand, and the desire to limit those health costs arising from the corresponding economic contraction on the other. This is especially the case if pandemic-control measures are seen as helping the former objective while harming the latter, though it is worth noting that it is still unclear the extent to which pandemic-control measures are responsible for the contraction caused by COVID- 19 .
} 
Likewise, turning to the Great Depression, a more recent and thus perhaps more comparable setting to today's, Stuckler et al. (2012) find at best mixed evidence of a beneficial health effect of the downturn: while there was a small reduction in all-cause mortality during this crisis, only those reductions in heart disease (small) and traffic fatalities (rather larger) could plausibly be linked to contemporaneous local economic shocks; other recession-related causes of death identified in the literature, such as suicide, rose substantially. Fishback et al. (2007) similarly find that had New Deal relief spending not intervened, the Great Depression would have created a "demographic disaster," depressing birth rates and elevating death rates relative to prior trends (particularly among infants, those perhaps most vulnerable to short-run income fluctuations). Their results emphasize the importance of government responses to economic crises that in turn become health crises (and vice-versa): for instance, they note that while all-cause non-infant mortality rates were largely unaffected by relief spending, such income support nevertheless did helped reduce rates of certain salient causes of death such as suicide, one of the few causes of adult mortality identified in Stuckler et al. (2012) as seeing a marked increase during the Great Depression.

\section{IV.b. The Long-Run Scarring Effects of Recessions}

While current debates around COVID-19 are understandably focused on the immediate impact of pandemic-induced recession conditions, the economic history literature teaches us that we should be equally-perhaps even more - concerned about the long-run scarring effects arising from this economic dislocation. Indeed, this channel may be especially relevant in more modern, high-income, and robustsafety net settings where most people survive an adverse shock, only to contend with the long-term and sometimes latent fallout. Some of these scarring effects stem from the immediate impact on household incomes. Depression-era resource deficits have been shown to affect cohorts that were in utero at the time well into adulthood, lowering their college completion rates and later-life incomes, and raising their rates of later-life poverty and disability - adverse effects that were only more pronounced in poorer areas, and areas that received less relief spending (Arthi, 2018; Fishback \& Thomasson, 2014). ${ }^{54}$

Meanwhile, other long-run penalties arise from disruptions to labor markets and human capital acquisition. A large contemporary literature studies the phenomenon of labor market scarring, or the idea that economic conditions at the time of labor market entry may have lasting effects on training decisions, occupational choice, career trajectories, and lifetime income. ${ }^{55}$ This evidence, much of it taken from college graduates around the 2008 Recession, is mixed: some studies suggest that the impact of initial labor market conditions diminishes over the course of an individual's career - often within the first decade — while others find that some penalties associated with early-career shocks can be cumulative and permanent (see Rothstein (2019) for an in-depth review; see also, Kahn (2010)). These effects are often heterogeneous by skill level, and may be driven by mismatch in initial job placement (Faberman \& Mazumder 2012, Liu et al. 2016, Oyer 2006, Şahin et al. 2014, van den Berge 2018), lower initial wages (which may be partially related to job mismatch; Oreopoulos et al. (2012)), reduced working time (Cockx \& Ghirelli 2016), and delays in finding employment (Genda et al. 2010), among other factors. Moreover, strategic responses to these shocks, such as migration (Feigenbaum 2015), temporary exit from the labor force (Hershbein 2012), and human capital acquisition (Charles et al. 2018, Barr \& Turner 2015), may themselves have implications for short- and long-run labor

\footnotetext{
${ }^{54}$ The stress of adverse shocks may also be transmitted intergenerationally through epigenetic channels. See, e.g., Costa et al. (2018). Likewise, there is evidence that both pandemics and recessions - as traumatic and stressful events - can shape the attitudes and preferences of those exposed during formative years in ways that can have lasting political and economic consequences (see, e.g., Campante et al. (2020); Giuliano \& Spilimbergo (2015); Malmendier \& Nagel (2011); and Schoar \& Zuo (2017)).

${ }^{55}$ While this literature focuses on adverse shocks at the time of labor market entry, note that compared to other recessions, long-run labor market scarring could even extend to a different and younger range of cohorts in the COVID-19 case, because of widespread school closures. Other COVID-19-related mechanisms, such as the loss of parental income, would tend to compound these effects further.
} 
market prospects, as separate from those arising directly from the initial shock. ${ }^{56}$ These studies thus strongly suggest that downturns may have important "overhang" that may potentially "reduce prosperity for decades to come," both for directly-affected cohorts and the wider economy (Rothstein 2019, p. 4). Accordingly, verylong-run and even intergenerational evidence on these issues can be especially valuable.

Recent work in economic history has looked to the Great Depression in order to offer precisely this sort of perspective. These studies show substantial and persistent penalties for all workers in severely-hit areas, but especially for new labor market entrants, who faced very different constraints and scope for adaptation than did incumbent workers. Moulton (2017), for instance, finds a substantial earnings penalty amongst less-educated American men just entering the labor market in 1930. While there are large adverse effects for those born in severely-affected states, this age-at-downturn penalty disappears in less-affected states. Likewise, examining evidence on labor force transitions using large-scale linked microdata from the U.S., Arthi et al. (2020b) show that many younger workers during the Depression accepted work that they otherwise might not have considered in better economic times-whether because of their now-dire need, the additional competition from older workers, or some combination of these factors. Moreover, many young people seeking work were locked out of the labor market completely by their older counterparts, who now remained in the labor force (or even re-entered it) at higher rates. Evidence on occupational transitions and socioeconomic mobility also suggest important career-stage gradients in scarring: younger workers were crowded out of the best local job opportunities by their older counterparts, with young workers in more rural areas pushed out of farming by older workers who retained these jobs, and into general laborer and non-occupational positions; and those in more industrial areas being pushed into farming, the less desirable class of occupations in these areas. Importantly, while both of these outcomes represent a short-run penalty for newer labor market entrants, the long-run implications for wellbeing may be very different, given the rapid urbanization and the incipient decline of the agricultural sector that was to come. Indeed, by providing the impetus to leave agriculture (or by prompting higher rates of outmigration-younger labor market cohorts irrespective of sector were also likelier to have moved across state lines or into urban areas during the Depression, perhaps in response to the dearth of local opportunities for inexperienced workers), the Great Depression may have had a small silver lining for young rural workers. However, at least in the short run, it served to hamper upward mobility - or even, to induce downward mobility. For instance, Liu \& Fishback (2019) show that though concerns over skill depreciation and mismatch during spells of un- or under-employment animated Depression-era policymakers, New Deal programs largely failed to match workers to jobs that used their skills, often resulting in lower incomes and transitions into lower-skilled employment or unemployment - though at least some general human capital was maintained. Meanwhile, Feigenbaum (2015) finds that by 1940, intergenerational mobility had fallen for men growing up in cities severely hit by the Depression. Migration - in particular, the superior destination choices of the sons of richer fathers - was an important mechanism behind these results, again emphasizing the capacity of large adverse shocks to exacerbate rather than level preexisting inequalities.

\section{Moving Forward}

The history of past pandemics and economic downturns provides sobering guidance for what we might expect from the current COVID-19 crisis. There is a complicated relationship between health and economic productivity that will shape the immediate and latent effects of COVID-19 in both obvious and subtle ways. Given that these latent effects unfold over decades and even generations, economic history is uniquely

\footnotetext{
56 While Charles et al. (2018) and Barr \& Turner (2015) discuss how recessions may induce voluntary changes in schooling patterns that in turn have career-long effects, Meyers \& Thomasson (2017) consider the long-run consequences of involuntary schooling disruptions due to a similarly disruptive event, the 1916 polio pandemic. They find that children on the cusp of school-leaving age never returned to school following temporary closures implemented to slow the spread of polio, resulting in lower lifetime educational attainment for these cohorts.
} 
capable of providing evidence on the potential long-term costs of the pandemic.

Experience from both historical pandemics and historical recessions can inform our view of the possible longrun effects of COVID-19, and how we might mitigate these costs. The experience of the 1918 influenza pandemic suggests that disease exposure can impact individuals throughout their lifetimes, both directly through poorer health, and indirectly through reduced investment in human capital. The costs were not limited to those individuals directly exposed; instead, they spilled over within households and across space, sectors and generations. Moreover, while mortality is salient, and the saving of lives remains perhaps the primary objective during a pandemic, avoiding and compensating for morbidity is arguably as important a matter of policy concern, especially in the context of possible long-run effects. Particularly in a pandemic where large shares of prime-aged people fall ill (as in the 1918 pandemic), or in pandemics where many are infected but ultimately survive (as in both the 1918 pandemic and COVID-19), experiences of pandemic illness may have lasting effects over the life-course, either through the initial illness (which may, for instance, compromise fetal nutrition, reduce work capacity, or permanently damage health) or through its sequelae later in life. The Great Depression points to other long-term effects that are likely to emerge from the pandemic-related slowdown in economic activity: both being born or entering the labor market during the Great Depression led to economic penalties well into adulthood, and constraints on migration had adverse effects on individuals and firms. Researchers and policymakers should therefore consider the potential for these long-run costs when weighing the short-term costs and benefits of pandemic control and fiscal intervention. History suggests potentially massive future costs for both the economy and the safety net arising from the dampened economic fortunes, chronic health issues, and foregone fertility of cohorts impacted by COVID-19. Given that human capital investments are generally more productive the earlier they are implemented, this suggests that policy interventions undertaken now, such as cash relief, could be especially cost-effective, and their net long-run benefits tremendous.

Economic history also reveals that we cannot think of the health and economic impacts of COVID-19 independently of one another. Past pandemics indicate that regardless of the pathology of a disease, its impacts are often a function of economic conditions. While some pandemics spared no class, many disproportionately impacted individuals of lower socioeconomic status due to a variety of factors including their occupations, living conditions, and access to healthcare. These individuals are at greater risk of exposure, face greater harms conditional on exposure, and are less able to remediate these harms. We have already seen this taking place with COVID-19, and need to remain aware that the spread of the disease and the severity of its effects will be in part a function of the spatial distribution of residence, economic activity, and environmental harms.

These disparate impacts of the virus itself will be compounded by the associated economic downturn. To the extent that the COVID-19 economic downturn limits exposure to environmental and work-related hazards, or reduces spending on unhealthy behaviors, non-coronavirus related dimensions of health may actually improve. However, both the modern literature on developing countries and the U.S.'s experience during the Great Depression suggest that the severe economic downturn may compound health problems in areas with lower baseline incomes and weaker safety nets. Identifying the channels through which income loss and general recession conditions impact health is necessary for properly interpreting any observed changes in population health levels during COVID-19, and for designing effective policies to safeguard health. Successful implementation of these policies also requires a firm understanding of history-roadblocks to public health initiatives during past pandemics associated with institutional structures and individual attitudes offer cautionary tales for our current crisis.

While economic history provides useful insights for the current pandemic, the way in which the pandemic is unfolding also provides a fresh perspective with which to revisit the past. We are witnessing the actions that individuals and families, workers and firms, citizens and public officials alike, take to guard against the pandemic, and the damage it has done to the economy. We are witnessing how these responses change 
as new information on COVID-19 emerges. The current pandemic affords us unprecedently rich and disaggregated data that, even while still evolving, can give new insights into which groups might warrant additional study in past pandemics. All of these dimensions of COVID-19 can help us reshape the roadmap for studying the economic history of pandemics.

One of the most important ways the COVID-19 experience can shape the direction of economic history may not be in seeking out the similarities but rather focusing on differences. While the rate of transmission and severity of the effects of COVID-19 have historical analogues, many relevant features of the world are meaningfully different-among them, the global nature of production; flows of people, goods, and information; urbanization; baseline living standards; medical technology; public health infrastructure; and the role of government. These differences can help us understand both past and present pandemics better; moreover, they help us understand how and why things have changed. For example, the COVID-19 shutdowns have been more far-reaching, and the corresponding economic downturn more damaging, than we might have predicted from previous pandemics. Can these differences explain the far greater economic costs of COVID-19 relative to similarly lethal pandemics of the 20th century?

This suggests an important direction for future economic history work: identifying why the nature of the response to public health crises differed, and why the resulting economic consequences were often smaller historically. Engaging in this work also allows us to grapple with challenging questions about tradeoffs between population health and economic activity. These tradeoffs are incredibly difficult to tackle head on in the face of an unfolding crisis; they force unfathomable but unavoidable choices on policymakers often working with limited information. By offering insight into not just the actions but also the short- and longrun outcomes of governments, firms, and individuals, economic history can guide us to better decisions in this and future crises.

\section{References}

Acemoglu, D., Johnson, S., \& Robinson, J. A. 2001. The colonial origins of comparative development: An empirical investigation. American economic review, 91(5), 1369-1401.

Acuna-Soto, Rodolfo, Viboud, Cecile, and Chowell, Gerardo. 2011. "Infuenza and Pneumonia Mortality in 66 Large Cities in the United States in Years Surrounding the 1918 Pandemic." PLOS ONE, 6(8): e23467.

Alfani, Guido. 2013. Plague in seventeenth-century Europe and the decline of Italy: an epidemiological hypothesis. European Review of Economic History, 17(4), 408-430.

Alfani, Guido and Murphy, Tommy. 2017. "Plague and Lethal Epidemics in the Pre-Industrial World." Journal of Economic History, 77(1): 314-343.

Almond, Douglas. 2006. "Is the 1918 Influenza Pandemic Over? Long-Term Effects of In utero Influenza Exposure in the Post-1940 U.S. Population." Journal of Political Economy, 114(4): 672-712.

Almond, Douglas and Currie, Janet. 2011. "Human Capital Development Before Age Five." Pages 13151486 of: Ashenfelter, Orley and Card, David (eds), Handbook of Labor Economics,Vol. 4, Part B. Amsterdam: North-Holland.

Almond, Douglas and Mazumder, Bhashkar. 2005. "The 1918 Influenza Pandemic and Subsequent Health Outcomes: An Analysis of SIPP Data." American Economic Review Papers \& Proceedings, 95(2): 258262.

Arthi, Vellore. 2018. "The Dust Was Long in Settling': Human Capital and the Lasting Impact of the American Dust Bowl." Journal of Economic History, 78(1): 196-230.

Arthi, Vellore, Beach, Brian, and Hanlon, W. Walker. 2020. "Recessions, Mortality, and Migration Bias: Evidence from the Lancashire Cotton Famine." Mimeo.

Arthi, Vellore, Beach, Brian, and Hanlon, W. Walker. 2017. "Estimating the Recession-Mortality Relationship When Migration Matters." NBER Working Paper \#23507. 
Arthi, Vellore, Eriksson, Katherine, and Richardson, Gary. 2020. "Labor Market Scarring in the Very Long Run: Evidence from Large-Scale Longitudinal Microdata." Mimeo.

Baird, Sarah, Friedman, Jed, \& Schady, Norbert. 2011. "Aggregate Income Shocks and Infant Mortality in the Developing World." Review of Economics and Statistics, 93(3): 847-856.

Barker, David, ed. 1992. Fetal and Infant Origins of Adult Disease: Papers. London: British Medical Journal.

Barr, Andrew and Sarah Turner. 2015. "Out of Work and Into School: Labor Market Policies and College Enrollment During the Great Recession.” Journal of Public Economics, 124: 63-73.

Barreca, Alan, Clay, Karen, and Tarr, Joel. 2014. "Coal, Smoke, and Death" Bituminous Coal and American Home Heating." NBER Working Paper \#19881.

Barro, R. J., Ursúa, J. F., \& Weng, J. 2020. The coronavirus and the great influenza pandemic: Lessons from the "Spanish Flu" for the coronavirus's potential effects on mortality and economic activity (No. w26866). National Bureau of Economic Research.

Basco, Sergi, Domènech, Jordi, and Rosés, Joan. 2020. "The Redistributive Effects of Pandemics: Evidence on the Spanish Flu." Universidad Carlos III de Madrid Working Papers in Economic History \#202005.

Beach, Brian, Clay, Karen, and Saavedra, Martin. Forthcoming. "The 1918 Influenza Pandemic and its Lessons for COVID-19." Journal of Economic Literature.

Beach, Brian, Ferrie, Joseph, and Saavedra, Martin. 2018. "Fetal Shock or Selection? The 1918 Influenza Pandemic and Human Capital Development." NBER Working Paper \#24725.

Bell, W. G. 1924. The Great Plague in London in 1665. The Great Plague in London in 1665.

Biraben, Jean Noël. 1975. Les Hommes et la Peste en France et dans Le Pays Européens et Méditerranées. Paris: Mouton.

Bleakley, H. 2003. Disease and development: Evidence from the American South. Journal of the European Economic Association, 1(2-3), 376-386.

Bleakley, H. 2007. Disease and development: evidence from hookworm eradication in the American South. The Quarterly Journal of Economics, 122(1), 73-117.

Bleakley, H. 2010. Malaria eradication in the Americas: A retrospective analysis of childhood exposure. American Economic Journal: Applied Economics, 2(2), 1-45.

Boberg-Fazlić, Nina, Ivets, Maryna, Karlsson, Martin, and Nilsson, Therese. 2017. "Disease and Fertility: Evidence from the 1918 Influenza Pandemic in Sweden." IZA Discussion Paper \#10834.

Brainerd, Elizabeth and Siegler, Mark. 2003. "The Economic Effects of the 1918 Influenza Epidemic," CEPR Discussion Paper \#3791.

Brown, Ryan and Thomas, Duncan. 2018. "On the Long Term Effects of the 1918 U.S. Influenza Pandemic." Mimeo.

Campante, Felipe, Durante, Ruben, and Depetris-Chauvin, Emilio. 2020. "The Virus of Fear: The Political Impact of Ebola in the U.S." NBER Working Paper No. 26897.

Carmichael, A. G. 2014. Plague and the poor in Renaissance Florence. Cambridge University Press.

Charles, Kerwin Kofi, Erik Hurst, and Matthew Notowidigdo. 2018. "Housing Booms and Busts, Labor Market Opportunities, and College Attendance.” American Economic Review, 108(10): 2947-2994.

Chay, Kenneth and Greenstone, Michael. 2005. "Does Air Quality Matter? Evidence from the Housing Market.” Journal of Political Economy, 113(21): 376-424.

Chay, Kenneth and Greenstone, Michael. 2003. "The Impact of Air Pollution on Infant Mortality: Evidence from Geographic Variation in Pollution Shocks Induced by a Recession." Quarterly Journal of Economics, 118(3): 1121-1167.

Chowell, Gerardo and Viboud, Cecile. 2016. "Pandemic Influenza and Socioeconomic Disparities: Lessons from 1918 Chicago." Proceedings of the National Academy of Sciences, 113(48): 13557-13559.

Chowell Gerardo, Bettencourt, Luis, Johnson, Niall, Alonso, Wladimire, Viboud, and Voboud, Cecile. 2008. "The 1918-1919 Influenza Pandemic in England and Wales: Spatial Patterns in Transmissibility and Mortality Impact.” Proceedings. Biological Sciences, 275(1634): 501-509. 
Clark, Gregory. 2007. A Farewell to the Alms: A Brief Economic History of the World. Princeton: Princeton University Press.

Clay, Karen, Lewis, Joshua, and Severnini, Edson. 2019. "What Explains Cross-City Variation in Mortality during the 1918 Influenza Pandemic? Evidence from 438 U.S. Cities." Economics and Human Biology, 35: 42-50.

Clay, Karen, Lewis, Joshua, and Severnini, Edson. 2018. "Pollution, Infectious Disease, and Mortality: Evidence from the 1918 Spanish Influenza Pandemic." Journal of Economic History, 78(4): 1179-1209.

Clay, Karen, Lewis, Joshua, and Severnini, Edson. 2016. "Canary in a Coal Mine: Infant Mortality, Property Values, and Tradeoffs Associated with Mid-20 ${ }^{\text {th }}$ Century Air Pollution." NBER Working Paper \#22155.

Cockx, Bart and Corinna Ghirelli. 2016. "Scars of Recessions in a Rigid Labor Market." Labour Economics, 41: 162-176.

Cook, C. Justin, Fletcher, Jason, and Forgues, Angela. 2019. "Multigenerational Effects of Early-Life Health Shocks.” Demography, 56: 1855-1874.

Correia, Sergio, Luck, Stephan, and Verner, Emil. 2020. "Pandemics Depress the Economy, Public Health Interventions Do Not: Evidence from the 1918 Flu." Mimeo.

Costa, Dora. 2015. "Health and the Economy in the United States from 1750 to the Present." Journal of Economic Literature, 53(3): 503-570.

Costa, Dora, Yetter, Noelle, and DeSomer, Heather. 2018. "Intergenerational Transmission of Paternal Trauma Among US Civil War Ex-POWs." Proceedings of the National Academy of Sciences, 115(44): 11215-11220.

Crosby, A. W. 2003. America's forgotten pandemic: the influenza of 1918. Cambridge University Press.

Currie, Janet, Davis, Lucas, Greenstone, Michael, and Walker, Reed. 2015. "Environmental Health Risks and Housing Values: Evidence from 1,600 Toxic Plant Openings and Closings." American Economic Review, 105(2): 678-709.

Curtis, Daniel. 2016. "Was Plague an Exclusively Urban Phenomenon? Plague Mortality in the Seventeenth-Century Low Countries." Journal of Interdisciplinary History, 47(2): 1-32.

Cutler, David, Huang, Wei, \& Lleras-Muney, Adriana. 2016. "Economic Conditions and Mortality: Evidence from 200 Years of Data." NBER Working Paper No. 22690.

Dawood, F. S., Iuliano, A. D., Reed, C., Meltzer, M. I., Shay, D. K., Cheng, P. Y., ... \& Feikin, D. R. (2012). Estimated global mortality associated with the first 12 months of 2009 pandemic influenza A H1N1 virus circulation: a modelling study. The Lancet infectious diseases, 12(9), 687-695.

Dehejia, Rajeev, \& Lleras-Muney, Adriana. 2004. “Booms, Busts, and Babies' Health.” Quarterly Journal of Economics, 119(3): 1091-1130.

Diamond, J. 1999. Guns, Germs, and Steel: The Fates of Human Societies. United Kingdom: W.W. Norton.

Dinges, M. 1995. Pest und Staat: von der Institutionengeschichte zur sozialen Konstruktion. Neue Wege in der Seuchengeschichte, 71-103.

Dittmar, J., \& Meisenzahl, R. R. 2017. State Capacity and Public Goods: Institutional Change, Human Capital, and Growth in Historic Germany.

Donaldson, Dave and Keniston, Daniel. 2014. "How Positive Was the Positive Check? Investment and Fertility in the Aftermath of the 1918 Influenza in India." Mimeo.

Dyal JW, Grant MP, Broadwater K, et al. 202. COVID-19 Among Workers in Meat and Poultry Processing Facilities - 19 States, April 2020. MMWR Morbidity Mortality Weekly Report 2020;69:557-561. DOI: http://dx.doi.org/10.15585/mmwr.mm6918e3

Echenberg, M. 2010. Plague ports: the global urban impact of bubonic plague, 1894-1901. NYU Press.

Eliason, Marcus, \& Storrie, Donald. 2009. "Does Job Loss Shorten Life? Journal of Human Resources." 44(2): 277-302.

Ellner, P. D. 1998. Smallpox: gone but not forgotten. Infection, 26(5), 263-269.

Faberman, R. Jason and Bhashkar Mazumder. 2012. "Is There a Skills Mismatch in the Labor Market?" Chicago Fed Letter, 300.

Feigenbaum, James. 2015. "Intergenerational Mobility during the Great Depression." Mimeo. 
Ferreira, Francisco, \& Schady, Norbert. 2009. "Aggregate Economic Shocks, Child Schooling, and Child Health." World Bank Research Observer, 24(2): 147-181.

Fishback, Price, Haines, Michael, \& Kantor, Shawn. 2007. "Births, Deaths, and New Deal Relief during the Great Depression." Review of Economics and Statistics, 89(1): 1-14.

Fishback, Price and Thomasson, Melissa. 2014. "Hard Times in the Land of Plenty: The Effect on Income and Disability Later in Life for People Born during the Great Depression." Explorations in Economic History, 54: 64-78.

Fletcher, Jason. 2018. "The Effects of In utero Exposure to the 1918 Influenza Pandemic on Family Formation." Economics and Human Biology, 30: 59-68.

Genda, Yuji, Ayako Kondo, and Souichi Ohta. 2010. "Long-term Effects of a Recession at Labor Market Entry in Japan and the United States." Journal of Human Resources, 45(1): 157-196.

Giuliano, Paola and Spilimbergo, Antonio. 2014. "Growing Up in a Recession." Review of Economic Studies, 81(2): 787-817.

Glezen, W. P. 1996. Emerging infections: pandemic influenza. Epidemiologic reviews, 18(1), 64-76.

Goolsbee, Austan and Syverson, Chad. 2020. "Fear, Lockdown, and Diversion: Comparing Divers of Pandemic Economic Decline 2020.” NBER Working Paper \#27432.

Grantz, Kyra, Rane, Madhura, Salje, Henrik, Glass, Gregory, Schachterle, Stephen, and Cummings, Derek. 2016. "Disparities in Influenza Mortality and Transmission Related to Sociodemographic Factors within Chicago in the Pandemic of 1918." Proceedings of the National Academy of Sciences, 113(48): 13839-13844.

Grantz, Kyra, Rane, Madhura, Salje, Henrik, Glass, Gregory, Schachterle, Stephen, and Cummings, Derek. 2016. "Reply to Shanks and Brundage: Many Plausible Mechanisms of Pandemic Mortality Disparities." Proceedings of the National Academy of Sciences, 114(18): E3588-E3589.

Griffith, Rachel, O'Connell, Martin, \& Smith, Kate. 2013. "Food Expenditure and Nutritional Quality over the Great Recession." Tech. rept.

Guerra, F. M., Bolotin, S., Lim, G., Heffernan, J., Deeks, S. L., Li, Y., \& Crowcroft, N. S. (2017). The basic reproduction number (R0) of measles: a systematic review. The Lancet Infectious Diseases, 17(12), e420-e428.

Guimbeau, Amanda, Menon, Nidhiya, and Musacchio, Aldo. 2020. "The Brazilian Bombshell? The LongTerm Impact of the 1918 Influenza Pandemic the South American Way." NBER Working Paper \#26929.

Gupta, Sumedha, Montenovo, Laura, Nguyen, Thuy, Lozano Rojas, Felipe, Schmutte, Ian, Simon, Kosali, Weinberg, Bruce, and Wing, Coady. 2020. "Effects of Social Distancing Policy on Labor Market Outcomes." NBER Working Paper \#27280.

Hatchett, Richard, Mecher, Carter, and Lipsitch, Marc. 2007. "Public Health Interventions and Epidemic Intensity during the 1918 Influenza Pandemic." Proceedings of the National Academy of Sciences, 104(18): 7582-7587.

Heckman, James. 2007. "The Economics, Technology, and Neuroscience of Human Capability Formation." Proceedings of the National Academy of Sciences, 104(33): 13250-13255.

Hershbein, Brad. 2012. "Graduating High School in a Recession: Work, Education, and Home Production." B.E. Journal of Economic Analysis \& Policy, 12(1): 1-29.

Hsiang, Solomon, Oliva, Paulina, and Walker, Reed. 2019. "The Distribution of Environmental Damages." Review of Environmental Economics and Policy, 13(1): 83-103.

Isenmann, E. 2014. Die deutsche Stadt im Mittelalter 1150-1550: Stadtgestalt, Recht, Verfassung, Stadtregiment, Kirche, Gesellschaft, Wirtschaft. Böhlau Verlag Köln Weimar.

Kahn, Lisa. 2010. "The Long-Term Labor Market Consequences of Graduating from College in a Bad Economy." Labour Economics, 17: 303-316.

Kahn, Lisa, Lange, Fabian, and Wiczer, David. 2020. "Labor Demand in the Time of COVID-19: Evidence from Vacancy Postings and UI Claims." NBER Working Paper \#27061.

Lilley, Andrew, Lilley, Matthew, and Rinaldi, Gianluca. 2020. "Public Health Interventions and Economic Growth: Revisiting the Spanish Flu Evidence.” Mimeo. 
Lin, Ming-Jen and Liu, Elaine. 2014. "Does In utero Exposure to Illness Matter? The 1918 Influenza Epidemic in Taiwan as a Natural Experiment." Journal of Health Economics, 37: 152-163.

Liu, Kai, Kjell Salvanes, and Erik Ø. Sørensen. 2016. "Good Skills in Bad Times: Cyclical Skill Mismatch and the Long-Term Effects of Graduating in a Recession." European Economic Review, 84: 3-17.

Liu, Xing and Fishback, Price. 2019. "Effects of New Deal Spending and the Downturns of the 1930s on Private Labor Markets in 1939/1940.” Explorations in Economic History, 71:25-54.

Malmendier, Ulrike and Stefan Nagel. 2011. "Depression Babies: Do Macroeconomic Experiences Affect Risk Taking?" Quarterly Journal of Economics, 126(1): 373-416.

Mamelund, Svenn-Erik. 2004. "Can the Spanish Influenza Pandemic of 1918 Explain the baby Boom of 1920 in Neutral Norway?" Population, 59: 229-260.

Mamelund, S. E. 2018. 1918 pandemic morbidity: The first wave hits the poor, the second wave hits the rich. Influenza and other respiratory viruses, 12(3), 307-313.

Mamelund, Svenn-Erik. 2006. "A Socially Neutral Disease? Individual Social Class, Household Wealth and Mortality from Spanish Influenza in Two Socially Contrasting Parishes in Kristiania 1918-19." Social Science and Medicine, 62: 923-940.

Markel, H., Lipman, H. B., Navarro, J. A., Sloan, A., Michalsen, J. R., Stern, A. M., \& Cetron, M. S. 2007. Nonpharmaceutical interventions implemented by U.S. cities during the 1918-1919 influenza pandemic. Jama, 298(6), 644-654.

McGuire, R. A., \& Coelho, P. R. 2011. Parasites, pathogens, and progress: diseases and economic development. MIT Press.

Meyers, Keith and Thomasson, Melissa. 2017. "Paralyzed by Panic: Measuring the Effect of School Closures during the 1916 Polio Pandemic on Educational Attainment." NBER Working Paper No. 23890.

Miller, Douglas L., Page, Marianne, Stevens, Ann Huff, \& Filipski, Mateusz. 2009. "Why Are Recessions Good for Your Health?" American Economic Review Papers \& Proceedings, 99(2): 122-127.

Miller, Grant, \& Urdinola, B Piedad. 2010. "Cyclicality, Mortality, and the Value of Time: The Case of Coffee Price Fluctuations and Child Survival in Colombia." Journal of Political Economy, 118(1): 113.

Morens, D. M., Folkers, G. K., \& Fauci, A. S. 2009. What is a pandemic? Journal of Infectious Diseases, 200(7), 1018-1021.

Moulton, Jeremy. 2017. "The Great Depression of Income: Historical Estimates of the Longer-Run Impact of Entering the Labor Market during a Recession." B.E. Journal of Economic Analysis \& Policy, 17(4): $1-20$.

Muller, Andreas. 1989. "Business Recession, Alcohol Consumption, Drinking and Driving Laws: Impact on Oklahoma Motor Vehicle Fatalities and Fatal Crashes." American Journal of Public Health, 79(10): 1366-1370.

Murray, Christopher, Lopez, Alan, Chin, Brian, Feehan, Dennis, and Hill, Kenneth. 2006. "Estimation of Potential Global Pandemic Influenza Mortality on the Basis of Vital Registry Data from the 1918-20 Pandemic: A Quantitative Analysis." Lancet, 368: 2211-2218.

Noymer, Andrew. 2011. "The 1918 Influenza Pandemic Hastened the Decline of Tuberculosis in the United States: An Age, Period, Cohort Analysis." Vaccine, 29S: B38-B41.

Nunn, N., \& Qian, N. 2010. The Columbian exchange: A history of disease, food, and ideas. Journal of Economic Perspectives, 24(2), 163-88.

Ogasawara, Kota. 2018. "The Long-Run Effects of Pandemic Influenza on the Development of Children from Elite Backgrounds: Evidence from Industrializing Japan." Economics and Human Biology, 31: 125-137.

Økland, H., \& Mamelund, S. E. 2019. Race and 1918 influenza pandemic in the United States: A review of the literature. International journal of environmental research and public health, 16(14), 2487.

Olson, Donald, Simonsen, Lone, Edelson, Paul, and Morse, Stephen. 2005. "Epidemiological Evidence of an Early Wave of the 1918 Influenza Pandemic in New York City." Proceedings of the National Academy of Sciences, 102(31): 11059-11063. 
Oreopoulos, Philip, Till von Wachter, and Andrew Heisz. 2012. "The Short- and Long-Term Career Effects of Graduating in a Recession.” American Economic Journal: Applied Economics, 4(1): 1-29.

Oyer, Paul. 2008. "The Making of an Investment Banker: Macroeconomic Shocks, Career Choice, and Lifetime Income." Journal of Finance, 63: 2601-2628.

Painter, Gary. 2010. "What Happens to Household Formation in a Recession?" 46th Annual AREUEA Conference Paper.

Parman, John. 2015. "Childhood Health and Sibling Outcomes: Nurture Forcing Nature during the 1918 Influenza Pandemic." Explorations in Economic History, 58: 22-43.

Patterson, K. D. 1992. Yellow fever epidemics and mortality in the United States, 1693-1905. Social science \& medicine, 34(8), 855-865.

Quinn, S. C., Kumar, S., Freimuth, V. S., Musa, D., Casteneda-Angarita, N., \& Kidwell, K. (2011). Racial disparities in exposure, susceptibility, and access to health care in the U.S. H1N1 influenza pandemic. American journal of public health, 101(2), 285-293.

Rothstein, Jesse. 2019. "The Lost Generation? Scarring after the Great Recession." Mimeo.

Ruhm, Christopher. 2000. "Are Recessions Good for Your Health?” Quarterly Journal of Economics, 115(2): 617-650.

Ruhm, Christopher. 2005. "Healthy Living in Hard Times." Journal of Health Economics, 24(2): 341-363.

Ruhm, Christopher, \& Black, William. 2002. "Does Drinking Really Decrease in Bad Times?" Journal of Health Economics, 21(4): 659-678.

S\&P Dow Jones Indices LLC, Dow Jones Industrial Average [DJIA], retrieved from FRED, Federal Reserve Bank of St. Louis; https://fred.stlouisfed.org/series/DJIA, May 7, 2020.

Saavedra, M. 2017. Early-life disease exposure and occupational status: The impact of yellow fever during the 19th century. Explorations in Economic History, 64, 62-81.

Şahin, Ayşegül, Joseph Song, Giorgio Topa, and Giovanni Violante. 2014. "Mismatch Unemployment." American Economic Review, 104(11): 3529-3564.

Sanche, S., Lin, Y. T., Xu, C., Romero-Severson, E., Hengartner, N., \& Ke, R. 2020. High Contagiousness and Rapid Spread of Severe Acute Respiratory Syndrome Coronavirus 2. Emerging infectious diseases, 26(7).

Schoar, Antoinette and Zuo, Luo. 2017. "Shaped by Booms and Busts: How the Economy Impacts CEO Careers and Management Styles," The Review of Financial Studies, 30(5): 1425-1456.

Shanks, G. Dennis and Brundage, John. 2017. "Variable Mortality during the 1918 Influenza Pandemic in Chicago." Proceedings of the National Academy of Sciences, 114(18): E3586-E3587.

Simonsen, L., Clarke, M. J., Williamson, G. D., Stroup, D. F., Arden, N. H., \& Schonberger, L. B. (1997). The impact of influenza epidemics on mortality: introducing a severity index. American journal of public health, 87(12), 1944-1950.

Slack, P. 1985. The impact of plague in Tudor and Stuart England. Taylor \& Francis.

Stevens, Ann Huff, Miller, Douglas, Page, Marianne, \& Filipski, Mateusz. 2015. "The Best of Times, the Worst of Times: Understanding Pro-cyclical Mortality." American Economic Journal: Economic Policy, 7(4): 279-311.

Stuckler, David, Meissner, Christopher, Fishback, Price, Basu, Sanjay, \& McKee, Martin. 2012. "Banking Crises and Mortality During the Great Depression: Evidence from U.S. Urban Populations, 19291937." Journal of Epidemiology and Community Health, 66(5): 410-419.

Sullivan, Daniel, \& von Wachter, Till. 2009. "Job Displacement and Mortality: An Analysis Using Administrative Data." Quarterly Journal of Economics, 124(3): 1265-1306.

Sydenstricker, E. 1931. The incidence of influenza among persons of different economic status during the epidemic of 1918. Public Health Reports (1896-1970), 154-170.

Tang, J. P. 2017. The Engine and the Reaper: Industrialization and mortality in late nineteenth century Japan. Journal of health economics, 56, 145-162.

Taubenberger, Jeffrey and Morens, David. 2006. "1918 Influenza: The Mother of All Pandemics." Emerging Infectious Diseases, 1291): 15-22. 
Troesken, Werner. 2015. The Pox of Liberty: How the Constitution Left Americans Rich, Free, and Prone to Infection. Chicago: University of Chicago Press.

Tuckel, Peter, Sassler, Sharon, Maisel, Richard, and Leykam, Andrew. 2006. "The Diffusion of the Influenza Pandemic of 1918 in Hartford, Connecticut.” Social Science History, 30(2): 167-196.

U.S. Bureau of Labor Statistics, Unemployment Rate [UNRATE], retrieved from FRED, Federal Reserve Bank of St. Louis; https://fred.stlouisfed.org/series/UNRATE, May 8, 2020.

van den Berge, Wiljan. 2018. "Bad Start, Bad Match? The Early Career Effects of Graduating in a Recession for Vocational and Academic Graduates." Labour Economics, 53: 75-96.

Velde, François. 2020. "What Happened to the US Economy During the 1918 Influenza Pandemic? A View Through High-Frequency Data." Federal Reserve Bank of Chicago Working Paper \#2020-11.

Voigtländer, Nico \& Voth, Hans-Joachim. 2013. "How the West 'Invented' Fertility Restriction.” American Economic Review, 103(6): 2227-2264.

Voigtländer, Nico \& Voth, Hans-Joachim. 2009. "Malthusian Dynamism and the Rise of Europe: Make War, Not Love." American Economic Review Papers \& Proceedings, 99(2): 248-254.

Voigtländer, Nico \& Voth, Hans-Joachim. 2013. "The Three Horsemen of Riches: Plague, War, and Urbanization in Early Modern Europe." Review of Economic Studies, 80: 774-811.

World Health Organization. 2000. WHO Report on Global Surveillance of Epidemic-prone Infectious Diseases.

World Health Organization. 2020. COVID-19 Strategy Update. April 14, 2020.

Young, Alwyn. 2005. "The Gift of the Dying: The Tragedy of AIDS and the Welfare of Future African Generations." Quarterly Journal of Economics, 120(2): 423-466. 